\title{
Validation of the Atmospheric Chemistry Experiment (ACE) version 2.2 temperature using ground-based and space-borne measurements
}

\author{
R. J. Sica ${ }^{1}$, M. R. M. Izawa ${ }^{2}$, K. A. Walker ${ }^{3,4}$, C. Boone ${ }^{3}$, S. V. Petelina ${ }^{5,6}$, P. S. Argall ${ }^{1}$, P. Bernath ${ }^{3,7}$, G. B. Burns ${ }^{8}$, \\ V. Catoire ${ }^{9}$, R. L. Collins ${ }^{10}$, W. H. Daffer ${ }^{11}$, C. De Clercq ${ }^{12}$, Z. Y. Fan ${ }^{3}$, B. J. Firanski ${ }^{13}$, W. J. R. French ${ }^{8}$, P. Gerard ${ }^{12}$, \\ M. Gerding ${ }^{14}$, J. Granville ${ }^{12}$, J. L. Innis ${ }^{8}$, P. Keckhut ${ }^{15}$, T. Kerzenmacher $^{4}$, A. R. Klekociuk ${ }^{8}$, E. Kyrö ${ }^{16}$, \\ J. C. Lambert ${ }^{12}$, E. J. Llewellyn ${ }^{5}$, G. L. Manney ${ }^{17,18}$, I. S. McDermid ${ }^{19}$, K. Mizutani ${ }^{20}$, Y. Murayama ${ }^{20}$, C. Piccolo ${ }^{21}$, \\ P. Raspollini ${ }^{22}$, M. Ridolfi ${ }^{23}$, C. Robert ${ }^{9}$, W. Steinbrecht ${ }^{24}$, K. B. Strawbridge ${ }^{13}$, K. Strong ${ }^{4}$, R. Stübi ${ }^{25}$, and \\ B. Thurairajah ${ }^{10}$
}

${ }^{1}$ Department of Physics and Astronomy, The University of Western Ontario, London, Ontario, Canada

${ }^{2}$ Department of Earth Sciences, The University of Western Ontario, London, Ontario, Canada

${ }^{3}$ Department of Chemistry, University of Waterloo, Waterloo, Ontario, Canada

${ }^{4}$ Department of Physics, University of Toronto, Ontario, Canada

${ }^{5}$ Institute of Space and Atmospheric Studies, University of Saskatchewan, Saskatoon, Canada

${ }^{6}$ Department of Physics, La Trobe University, Victoria, Australia

${ }^{7}$ Department of Chemistry, University of York, UK

${ }^{8}$ Ice, Ocean, Atmosphere and Climate Program, Australian Antarctic Division, Kingston, Tasmania, Australia

${ }^{9}$ Laboratoire de Physique et Chimie de l'Environnement, CNRS - Universite d'Orleans, France

${ }^{10}$ Geophysical Institute and Atmospheric Sciences Program, University of Alaska Fairbanks, Alaska

${ }^{11}$ Columbus Technologies Inc., Pasadena, California, USA

${ }^{12}$ Institut d'Aeronomie Spatiale de Belgique (IASB-BIRA), Brussels, Belgium

${ }^{13}$ Science and Technology Branch, Environment Canada, CARE, Egbert, Ontario, Canada

${ }^{14}$ Leibniz-Institute of Atmospheric Physics, Kühlungsborn, Germany

${ }^{15}$ Service d'Aéronomie, Institut Pierre Simon Laplace-UVSQ, Verrires-le-Buisson, France

${ }^{16}$ Finnish Meteorological Institute - Arctic Research Centre, Sodankylä, Finland

${ }^{17}$ Jet Propulsion Laboratory, California Institute of Technology, Pasadena, California, USA

${ }^{18}$ New Mexico Institute of Mining and Technology, Socorro, New Mexico, USA

${ }^{19}$ Jet Propulsion Laboratory, California Institute of Technology, Table Mountain Facility, Wrightwood, California, USA

${ }^{20}$ National Institute of Information and Communications Technology, Tokyo, Japan

${ }^{21}$ Department of Atmospheric, Oceanic and Planetary Physics, Clarendon Laboratory, Oxford, UK

${ }^{22}$ Istituto di Fisica Applicata "Nello Carrara" (IFAC) del Consiglio Nazionale delle Ricerche (CNR), Sesto Fiorentino,

Firenze, Italy

${ }^{23}$ Dip. di Chimica Fisica e Inorganica, University of Bologna, Bologna, Italy

${ }^{24}$ Deutsche Wetterdienst (DWD), Hohenpeissenberg Observatory, Germany

${ }^{25}$ Federal Office of Meteorology and Climatology, MeteoSwiss Aerological Station, Payerne, Switzerland

Received: 31 July 2007 - Published in Atmos. Chem. Phys. Discuss.: 23 August 2007

Revised: 7 November 2007 - Accepted: 27 November 2007 - Published: 8 January 2008

$\overline{\text { Correspondence to: } \mathrm{R} . \mathrm{J}}$. Sica

(sica@uwo.ca)

Published by Copernicus Publications on behalf of the European Geosciences Union. 
Abstract. An ensemble of space-borne and ground-based instruments has been used to evaluate the quality of the version 2.2 temperature retrievals from the Atmospheric Chemistry Experiment Fourier Transform Spectrometer (ACE-FTS). The agreement of ACE-FTS temperatures with other sensors is typically better than $2 \mathrm{~K}$ in the stratosphere and upper troposphere and $5 \mathrm{~K}$ in the lower mesosphere. There is evidence of a systematic high bias (roughly 3-6 K) in the ACE-FTS temperatures in the mesosphere, and a possible systematic low bias (roughly $2 \mathrm{~K}$ ) in ACE-FTS temperatures near $23 \mathrm{~km}$. Some ACE-FTS temperature profiles exhibit unphysical oscillations, a problem fixed in preliminary comparisons with temperatures derived using the next version of the ACE-FTS retrieval software. Though these relatively large oscillations in temperature can be on the order of $10 \mathrm{~K}$ in the mesosphere, retrieved volume mixing ratio profiles typically vary by less than a percent or so. Statistical comparisons suggest these oscillations occur in about $10 \%$ of the retrieved profiles. Analysis from a set of coincident lidar measurements suggests that the random error in ACE-FTS version 2.2 temperatures has a lower limit of about $\pm 2 \mathrm{~K}$.

\section{Introduction}

Beyond its obvious implications in climate and weather, temperature plays a fundamental role in Earth's atmosphere, influencing such things as dynamics, aerosol formation, and atmospheric chemistry. Limb-sounding satellite measurements provide temperature profiles with the high vertical resolution (on the order of a few $\mathrm{km}$ ) and global coverage needed to investigate these influences. Knowledge of temperature and pressure as a function of altitude is also required in the retrieval of atmospheric constituents $\left(\mathrm{O}_{3}, \mathrm{H}_{2} \mathrm{O}, \mathrm{CH}_{4}\right.$, etc.) from atmospheric limb measurements obtained by satellite instruments, primarily those operating in the infrared. Thus, it is necessary to evaluate the quality of these temperature retrievals for their use in scientific studies and for their impacts on trace gas retrievals.

This paper focuses on temperature validation studies for the Atmospheric Chemistry Experiment (ACE). ACE, also known as SCISAT-1, is a Canadian-led satellite mission for remote sensing of Earth's atmosphere, launched August 2003 into a $650 \mathrm{~km}$ circular orbit inclined $74^{\circ}$ to the equator (Bernath et al., 2005). Scientific measurements for the mission commenced in late February 2004. With its highinclination orbit, more than $50 \%$ of the measurements collected over the course of a year occur over the Arctic and Antarctic, as befits the primary mission objective to study polar ozone. ACE performs solar occultation measurements of the Earth's limb and, from these observations, profiles of atmospheric temperature and trace gas concentrations are retrieved.
For the past 30 years, space-borne limb-viewing spectrometers and radiometers have been used to derive high vertical resolution atmospheric temperature profiles, over altitudes ranging from the upper troposphere to the upper stratosphere and mesosphere. The first of these instruments was the Limb Radiance Inversion Radiometer (LRIR) on-board Nimbus-6, which measured emission from stratospheric and mesospheric $\mathrm{CO}_{2}$ in the $15 \mu \mathrm{m}$ region (Gille et al., 1980a,b). This work demonstrated the advantages of limb observations over nadir measurements, notably their higher vertical resolution and altitude coverage, for studying temperature in the stratosphere and mesosphere. However, the horizontal resolution is lower for the limb sounding instruments, as typical path lengths are on the order of $500 \mathrm{~km}$. Development of the infrared limb emission measurement technique continued in the 1980s and 1990s with the Limb Infrared Monitor of the Stratophere (LIMS) (Gille et al., 1980b, 1984) and the Stratospheric and Mesospheric Sounder (SAMS) (Drummond et al., 1980; Rodgers et al., 1984) on the Nimbus7 platform; the Improved Stratospheric and Mesospheric Sounder (ISAMS) (Taylor et al., 1993; Dudhia and Livesey, 1996) and the Cryogenic Limb Array Etalon Spectrometer (CLAES) (Gille et al., 1996) on the Upper Atmosphere Research Satellite (UARS); and the Cryogenic Infrared Spectrometers and Telescopes for the Atmosphere (CRISTA) (Offermann et al., 1999; Riese et al., 1999) instrument that flew as part of the ATLAS-3 Space Shuttle mission.

In parallel with these limb emission measurements, instruments for solar absorption observations were used for limb occultation studies from orbit. These initial studies focused on aerosol and trace gas measurements (e.g. the Stratospheric Aerosol Measurement (SAM, SAM-II) and Stratospheric Aerosol and Gas Experiment (SAGE) programs (e.g. McCormick et al., 1979). The first temperatures obtained from occultation measurements were retrieved by the Atmospheric Trace MOlecule Spectroscopy (ATMOS) experiment, which flew four times on the Space Shuttle between 1985 and 1994 (Gunson et al., 1996; Stiller et al., 1995; Irion et al., 2002). Both ATMOS and the Halogen Occultation Experiment (HALOE) on UARS (Russell et al., 1993) used $\mathrm{CO}_{2}$ measurements in the infrared for their retrievals. More recently, the Improved Limb Atmospheric Sounder II (ILAS-II) (Nakajima et al., 2006; Sugita et al., 2004; Yamamori et al., 2006) on the ADvanced Earth Observing Satellite II (ADEOS-II) used occultation measurements of the $\mathrm{O}_{2}$ A-band to determine temperature profiles on a routine basis. In addition, techniques for using microwave measurements of $\mathrm{O}_{2}$ for temperature sounding were developed for the Microwave Limb Sounder (MLS), which flew on UARS, (Barath et al., 1993; Livesey et al., 2003) and the Millimeter-wave Atmospheric Sounder (MAS), which was part of the ATLAS-1, -2 and -3 Shuttle payloads (Croskey et al., 1992; von Engeln et al., 1998). Measurements of $\mathrm{O}_{2}$ in the visible were used for temperature retrievals from the High Resolution Doppler Imager (HRDI) (Hays et al., 1993; 
Ortland et al., 1998), which was also part of the UARS payload.

Of the spectrometers and radiometers currently on-orbit there are four, in addition to ACE, which are routinely producing temperature profiles using limb measurements. All use atmospheric emission signals to retrieve temperature profiles. Three instruments, the Michelson Interferometer for Passive Atmospheric Sounding (MIPAS) on ENVISAT (Fischer et al., 2007), the High Resolution Dynamics Limb Sounder (HIRDLS) on-board Earth Observing System (EOS) Aura (Gille et al., 2007 ${ }^{1}$; Francis et al., 2006) and the Sounding of the Atmosphere using Broadband Emission Radiometry (SABER) instrument on the Thermosphere Ionosphere Mesosphere Energetics and Dynamics (TIMED) satellite (Russell et al., 1999), measure infrared $\mathrm{CO}_{2}$ features while the other, the MLS instrument on the EOS Aura satellite (Aura/MLS) (Waters et al., 2006; Froidevaux et al., 2006; Schwartz et al., 2007), measures emission from $\mathrm{O}_{2}$ in the microwave region of the spectrum. Results from these instruments have been compared to the ACE temperature results as part of this and related validation studies (Schwartz et al., 2007; Gille et al., 2007 ${ }^{1}$ ). For other satellite missions using limb-scanning instruments, such as the Optical Spectrograph and Infrared Imaging System (OSIRIS) and the Submillimeter Radiometer (SMR) (Murtagh et al., 2002; Baron et al., 2001; Ridal et al., 2002) on Odin (Murtagh et al., 2002; Haley and McDade, 2002) temperature retrieval methods have been investigated as research products, however no routine data products are available for comparisons at this time.

This paper describes the quality of the current ACE-FTS temperature retrievals based on comparisons with measurements from satellite, ground-based and balloon-borne instruments. Section 2 outlines the data sets used in the comparisons and the specific comparisons are described in Sect. 3. Based on the results of these comparisons, improvements have been implemented for the temperature retrievals for the next data release. These are discussed in Sect. 4. Section 5 presents conclusions and recommendations for usage of the current ACE-FTS temperature data product in scientific studies.

\footnotetext{
${ }^{1}$ Gille, J., Barnett, J., Arter, P., Barker, M., Bernath, P., Boone, C., Cavanaugh, C., Chow, J., Coffey, M., Craft, J., Craig, C., Dials, M., Dean, V., Eden, T., Edwards, D. P., Francis, G., Halvorson, C., Harvey, L., Hepplewhite, C., Kinnison, D., Khosravi, R., Krinsky, C., Lambert, A., Lyjak, L., Lee, H., Loh, J., Mankin, W., McInerney, J., Moorhous, J., Massie, S., Nardi, B., Packman, D., Randall, C., Reburn, J., Rudolf, W., Schwartz, M., Serafin, J., Stone, K., Torpy, B., Walker, K., Waterfall, A., Watkins, R., Whitney, J., Woodard, D., and Young, G.: The High Resolution Dynamics Limb Sounder (HIRDLS): Experiment Overview, Results and Validation of Initial Temperature Data, J. Geophys. Res., in review, 2007.
}

\section{Instruments}

\subsection{Satellite}

\subsubsection{ACE-FTS}

The Atmospheric Chemistry Experiment Fourier Transform Spectrometer (ACE-FTS) is the primary instrument on board SCISAT-1 (Bernath et al., 2005). It is a high resolution $\left(0.02 \mathrm{~cm}^{-1}\right)$ infrared spectrometer featuring broad spectral coverage from 750 to $4400 \mathrm{~cm}^{-1}$. The solar occultation technique provides up to 30 occultations each day. The signal-tonoise ratio of ACE-FTS measurements is very high, between 300:1 and 400:1 near the center of the wavenumber range.

Profiles as a function of altitude for temperature and more than 30 trace gases are retrieved from ACE-FTS measurements. The details of ACE-FTS processing are described in Boone et al. (2005). Briefly, temperature and pressure profiles are determined over the altitude range 12 to $115 \mathrm{~km}$ using a non-linear least squares global fit approach. $\mathrm{CO}_{2}$ spectral features are fit using a total of 106 narrow spectral intervals called microwindows (typically $0.3-0.5 \mathrm{~cm}^{-1}$ wide for temperature retrievals) in the wavenumber ranges 930 $940 \mathrm{~cm}^{-1}, 1890-2450 \mathrm{~cm}^{-1}$, and $3300-3400 \mathrm{~cm}^{-1}$. The HITRAN 2004 spectroscopic database (Rothman et al., 2005) is used in the forward model calculations. The $\mathrm{CO}_{2}$ volume mixing ratio profile is fixed below about $70 \mathrm{~km}$. ACE-FTS temperatures and pressures below $12 \mathrm{~km}$ are fixed to data from the Canadian Meteorological Center (Gauthier et al., 1999; Laroche et al., 1999).

The pressure/temperature retrieval is separated into two altitude regions. At high altitudes (above $43 \mathrm{~km}$ ), pointing information used in the retrievals is based on simple geometry, derived from knowledge of the satellite's position in its orbit. At low altitudes (below $43 \mathrm{~km}$ ), refraction effects and the presence of clouds prohibit the use of simple geometry, and pointing information is therefore derived from analysis of the spectra.

The ACE-FTS instrument collects measurements every $2 \mathrm{~s}$. This sampling rate yields a typical altitude spacing of 3-4 km for measurements within an occultation, neglecting the effects of refraction that compress the spacing at low altitudes. Note that the altitude spacing within an occultation can range from $1.5-6 \mathrm{~km}$, depending on the geometry of the satellite's orbit for the given occultation. The actual altitude resolution achievable with the ACE-FTS is limited to about $3-4 \mathrm{~km}$, a consequence of the instrument's fieldof-view $(1.25 \mathrm{mrad}$ diameter aperture and $650 \mathrm{~km}$ orbit altitude). For the purpose of forward model calculations, retrieved quantities are interpolated from the "measurement grid" onto a standard 1-km grid using a piecewise quadratic approach.

The current version of the ACE-FTS data products is version 2.2 with updates for $\mathrm{O}_{3}, \mathrm{HDO}$ and $\mathrm{N}_{2} \mathrm{O}_{5}$. Initial validation studies for ACE-FTS temperature retrievals were 
performed using the version 1.0 data products. For version 1.0, comparisons with the HALOE instrument on UARS showed agreements of $\pm 2 \mathrm{~K}$ (McHugh et al., 2005). Kerzenmacher et al. (2005) compared the version 1.0 temperature profiles with radiosonde and lidar measurements from Eureka taken during the 2004 Canadian Arctic ACE Validation Campaign. The differences were less than $\pm 2.5 \mathrm{~K}$ from 10 $30 \mathrm{~km}$ and $17-45 \mathrm{~km}$, respectively. Recent comparisons of ACE-FTS version 2.2 temperatures with Aura/MLS showed that the two instruments differ by no more than $1.5 \mathrm{~K}$ in the stratosphere and that ACE-FTS reports higher temperatures by $5-7 \mathrm{~K}$ at higher altitudes (Schwartz et al., 2007). Gille et al. (2007) ${ }^{1}$ also compared HIRDLS temperature profiles with ACE-FTS results as part of their initial validation. The ACEFTS and HIRDLS temperatures agree within $\pm 3 \mathrm{~K}$ between 200-1 hPa.

In addition to ACE-FTS, there is a second solar occultation instrument on SCISAT-1. The Measurement of Aerosol Extinction in the Stratosphere and Troposphere Retrieved by Occultation (MAESTRO) is a dual, diode-array spectrometer measuring in the UV-visible-near-infrared spectral region (McElroy et al., 2007). Currently, its trace gas retrieval process (version 1.2) uses the temperature and pressure profiles obtained from the ACE-FTS measuremements. Future ACEMAESTRO data products will include temperature profiles derived from $\mathrm{O}_{2}$ and $\mathrm{H}_{2} \mathrm{O}$ spectra (Nowlan et al., 2007).

\subsubsection{SABER}

The TIMED satellite is an ongoing mission focused primarily on the mesosphere-lower thermosphere region (Russell et al., 1999). It was launched in December 2001 into a $650 \mathrm{~km}$ orbit with a period of $1.7 \mathrm{~h}$ and an inclination of $74.1^{\circ}$. SABER, one of four instruments on TIMED, is a 10-channel broadband limb scanning infrared radiometer that covers the spectral range of 1.27 to $17 \mu \mathrm{m}$. SABER measures vertical profiles of temperature, pressure, $\mathrm{O}_{3}, \mathrm{CO}_{2}, \mathrm{H}_{2} \mathrm{O}$, volume emission rates of $\mathrm{NO}(5.3 \mu \mathrm{m}), \mathrm{OH}$ Meinel bands, and $\mathrm{O}_{2}\left({ }^{1} \Delta\right)$, as well as deriving rates of radiative heating and cooling from the troposphere to the thermosphere. Atomic $\mathrm{O}$ and $\mathrm{H}$ are retrieved from the $\mathrm{O}_{2}\left({ }^{1} \Delta\right)$ and $\mathrm{OH}$ measurements. The data are provided on a vertical grid with the spacing of approximately $0.4 \mathrm{~km}$, which is the measurement sampling grid. The SABER instrument's field-of-view is $1.8 \mathrm{~km}$ and the vertical resolution is $2.2 \mathrm{~km}$.

SABER temperature profiles, version 1.06, are retrieved from two channels in the $\mathrm{CO}_{2} 15 \mu \mathrm{m}$ band using nonlocal thermodynamic equilibrium radiative transfer techniques (Mertens et al., 2001). The quality analysis for the SABER temperature retrievals showed a good agreement, better than $2 \mathrm{~K}$, with the UK Met Office assimilated analysis at altitudes below $70 \mathrm{~km}$ (Remsberg et al., 2003) and a systematic difference of up to $10 \mathrm{~K}$ in the upper mesosphere (Mertens et al., 2004; Petelina et al., 2005) compared to climatology derived from falling sphere data (Lübken, 1999).
It has been recently demonstrated that accounting for the redistribution of the $v_{2}$ quanta among the first excited levels of various $\mathrm{CO}_{2}$ isotopes significantly improves the agreement between SABER temperatures and the climatology above $70 \mathrm{~km}$ (Kutepov et al., 2006). As the improved version of SABER data are not yet available, ACE-FTS temperature retrievals are compared with the current SABER version 1.06 temperature retrievals in the altitude range of 12 to $70 \mathrm{~km}$, where there is a good agreement with other measurements.

\subsubsection{MIPAS}

MIPAS is an infrared limb-sounding Fourier transform interferometer on board the ENVISAT satellite, launched in March 2002 (Fischer et al., 2007). It measures atmospheric emission spectra over the range $685-2410 \mathrm{~cm}^{-1}$ (14.5-4.1 $\mu \mathrm{m})$, which includes the vibration-rotation bands of many molecules of interest. It is capable of measuring continuously around an orbit in both day and nighttime. With its rearward view along the orbit track and ENVISAT's sunsynchronous orbit, complete global coverage is obtained in $24 \mathrm{~h}$.

From July 2002 until March 2004 MIPAS was operated at full spectral resolution $\left(0.025 \mathrm{~cm}^{-1}\right)$, with a nominal limbscanning sequence of 17 steps with $3 \mathrm{~km}$ tangent height spacing in the troposphere and stratosphere, generating complete profiles spaced approximately every $500 \mathrm{~km}$ along the orbit. MIPAS operations were suspended in March 2004 following problems with the interferometer slide mechanism. Operations resumed in January 2005 with a reduced spectral resolution $\left(0.0625 \mathrm{~cm}^{-1}\right)$, a reduced duty cycle and a different limb scanning sequence, but only measurements from the full resolution mission are discussed here.

For the full spectral resolution mission, ESA have processed pressure/temperature and six key species $\left(\mathrm{H}_{2} \mathrm{O}, \mathrm{O}_{3}\right.$, $\mathrm{HNO}_{3}, \mathrm{CH}_{4}, \mathrm{~N}_{2} \mathrm{O}$ and $\mathrm{NO}_{2}$ ). The algorithm used for the Level 2 analysis is based on the Optimised Retrieval Model (Ridolfi et al., 2000; Raspollini et al., 2006). The retrieval uses microwindows not wider than $3 \mathrm{~cm}^{-1}$ in order to obtain the best information on the target parameters, as well as to avoid the analysis of spectral regions strongly affected by systematic errors (Dudhia et al., 2002). A non-linear least squares criterion without use of a priori information is adopted for the retrieval of each vertical profile. Each profile is retrieved using simultaneously the spectral measurements of a complete limb scanning sequence, i.e. using the global fit approach (Carlotti, 1988). The MIPAS version 4.62 data products were used in these comparisons. These profiles were found to agree with radiosonde, lidars and groundbased and balloon borne measurements to better than $1-2 \mathrm{~K}$ (Ridolfi et al., 2007). 


\subsubsection{HALOE}

The HALOE instrument was launched September 1991 on board the UARS platform into a $585 \mathrm{~km}$ circular orbit with an inclination of $57^{\circ}$ (Russell et al., 1993). Scientific measurements from the instrument extend from October 1991 through November 2005, and consist of vertical profiles for $\mathrm{O}_{3}, \mathrm{HF}, \mathrm{HCl}, \mathrm{H}_{2} \mathrm{O}, \mathrm{CH}_{4}, \mathrm{NO}, \mathrm{NO}_{2}$, temperature, and aerosol extinction at latitudes between $\pm 80^{\circ}$. The HALOE processing version used in this study is the third public release (V19).

HALOE took measurements in solar occultation with four radiometer channels and four dual radiometer/gas-filter correlation channels. The instantaneous field-of-view of the instrument at the limb tangent point was approximately $2 \mathrm{~km}$ vertical by $5 \mathrm{~km}$ horizontal. After processing, the effective altitude resolution was $3-5 \mathrm{~km}$, depending on altitude and channel. Temperature retrievals employed the transmission measurements in the $3570 \mathrm{~cm}^{-1}$ radiometer channel. With $\mathrm{CO}_{2}$ fixed to an assumed value, the retrieval moved upward from $35 \mathrm{~km}$ to $85 \mathrm{~km}$ in a hydrostatically-constrained process, iterating several times. Below $35 \mathrm{~km}$, temperatures from the National Centers for Environmental Prediction were used. Forward model calculations employed the HITRAN 1992 spectroscopic database, augmented by specific lab measurements in certain regions.

\subsection{Ground-based and balloon-borne instrumentation}

\subsubsection{Davis, Antarctica Rayleigh-scatter lidar}

Temperature profiles were obtained with a Rayleigh lidar from about 25 to $75 \mathrm{~km}$ at Davis, Antarctica $\left(68.6^{\circ} \mathrm{S}\right.$, $78.0^{\circ} \mathrm{E}$ ). Basic details of this instrument are provided by Klekociuk et al. (2003). In the lidar transmitter, $532 \mathrm{~nm}$ pulsed laser light is directed towards the zenith in a beam with $0.1 \mathrm{mrad}$ divergence. The laser pulses have a repetition rate of $50 \mathrm{~Hz}$ and typical pulse energy of $300 \mathrm{~mJ}$. During early 2005 , the original receiving telescope was replaced by a $300 \mathrm{~mm}$ aperture Schmidt-Cassegrain telescope. The new telescope is coupled to the detector by an optical fibre, and includes an autoguiding beam alignment system. The converging output beam of the telescope is incident on a pellicle beamsplitter, inclined at $45^{\circ}$ to the optical axis. Approximately $90 \%$ of the incident light passes through the beamsplitter and this beam enters the optical fibre. A CCD detector is located at the focal plane of the reflected beam. Images from the detector are analysed to correct the position of the telescope in real time so as to maintain accurate alignment of the transmitter and receiver fields-of-view. The images and telescope position information are available off-line to check the quality of the alignment.

The output of the optical fibre is chopped by a rotating shutter, and then collimated and filtered prior to being detected by a fast photomultiplier operating in photon-counting mode. The rotating shutter is phase-locked to the pulsing of the laser and is phased to protect the photomultiplier from high light levels, which would otherwise produce excessive pulse pile-up and after-pulse effects. The optical filter is a $0.3 \mathrm{~nm}$ bandpass interference filter, which can be augmented by one or two Fabry-Perot etalons during twilight or daytime respectively, to reduce the solar background. The optical fibre which couples the telescope to the detector is also changed depending on observing mode. A $910 \mu \mathrm{m}$ diameter fibre is used for night-time observations (during winter), while a $365 \mu \mathrm{m}$ diameter fibre is used during daytime observations (during summer). The smaller fibre reduces the background levels but requires tighter tolerances for autoguiding.

\subsubsection{Davis, Antarctica scanning spectrometer}

Hydroxyl airglow spectra are collected at Davis station, Antarctica $\left(68.6^{\circ} \mathrm{S}, 78.0^{\circ} \mathrm{E}\right)$ using a $1.26 \mathrm{~m}$ f/9 CzernyTurner scanning spectrometer with a cooled gallium-arsenide (GaAs) photomultiplier detector (Greet et al., 1998). Routine nightly observations of the $\mathrm{OH}(6-2) \mathrm{P}$-branch rotational lines $(\lambda=839$ to $851 \mathrm{~nm})$ are made in the zenith $\left(5.3^{\circ}\right.$ field-ofview) between mid-February ( $\sim$ day 048 ) and the end of October ( $\sim$ day 300 ) each year, when the solar depression angle is greater than $6^{\circ}$. The instrument bandwidth of $0.16 \mathrm{~nm}$ is sufficient to separate the P-branch lines (separation $\sim 2 \mathrm{~nm}$ ) but insufficient to resolve the lambda doubling in each line. Spectra are acquired in approximately $7 \mathrm{~min}$ and the analysis interpolates P-branch line intensities between successive scans. The instrument is operated in all cloud and auroral conditions. Burns et al. (2002) has examined the effect of cloud and aurora on rotational temperature determination and find they can operate and obtain temperatures successfully in these conditions.

Instrument response calibration is maintained by regularly scanning a low brightness source which uniformly illuminates the instrument's field-of-view. This source is annually cross referenced to standard lamps at the National Measurement Institute (NMI) in Australia or the National Institute of Science and Technology (NIST) in the USA. Rotational temperature uncertainties due to the annual response calibration are less than $0.3 \mathrm{~K}$ for all measurements considered in this comparison. Rotational temperatures are derived using the Langhoff et al. (1986) transition probabilities. These transition probabilities yield temperatures which are $\sim 2 \mathrm{~K}$ higher than those determined with a set of transition probability ratios derived from high signal-to-noise ratio spectra (French et al., 2000).

\subsubsection{London, Canada lidar}

The University of Western Ontario's Purple Crow Lidar (PCL) is a monostatic system capable of high temporalspatial temperature measurements using Rayleigh scatter from 30 to above $100 \mathrm{~km}$, depending on integration time 
and range binning, as well as vibrational Raman scattering from approximately 10 to $40 \mathrm{~km}$ (Argall et al., 2007). The lidar's transmitter is a frequency-doubled $\mathrm{Nd}$ :YAG laser with a pulse energy of nominally $600 \mathrm{~mJ}$ and a pulse repetition rate of $20 \mathrm{~Hz}$. The receiver is a $2.65 \mathrm{~m}$ diameter liquid mercury mirror. The lidar is located at The University of Western Ontario's Delaware Observatory $\left(42.9^{\circ} \mathrm{N}, 81.4^{\circ} \mathrm{W}\right)$. Details of the apparatus are available in Sica et al. (1995). The temperature analysis employed is based on the scheme described by Chanin and Hauchecorne (1984), which requires an initial seed temperature at the top of the measurement region to determine the temperature profile. The choice of temperature is an uncertainty whose contribution to the total error is not known precisely without an independent knowledge of the true temperature. The contribution of this uncertainty decreases by a factor of 10 approximately every 2 scale heights below the initial height of the integration. If the model atmosphere seed temperatures are accurate to $10 \%$ (e.g. $20 \mathrm{~K}$ ), then in the upper mesosphere the effect of the seed temperature is on the order $2 \mathrm{~K}$ or less for this study, as the integration of the individual profiles began at or above $95 \mathrm{~km}$. Of course if the seed temperatures are accurate to $1 \%$, the contribution to the total error is only $0.2 \mathrm{~K}$ in the mesosphere.

Of particular relevance to this study is the robustness of the Rayleigh-scatter temperature retrieval. Leblanc et al. (1998) present a study on the testing of Rayleigh lidar temperature retrieval routines. The data analysis routines used for the PCL climatology were tested using a similar synthetic data set to that described in Leblanc et al. (1998), and were found to accurately retrieve Rayleigh-scatter temperatures in the presence of noise and ozone (Sica et al., 2001).

\subsubsection{Kühlungsborn, Germany lidar}

Temperature soundings from 1 to $105 \mathrm{~km}$ altitude are performed by the combination of a potassium resonance lidar (von Zahn and Höffner, 1996) and a Rayleigh-Mie-Raman (RMR) lidar system (Alpers et al., 2004) at the LeibnizInstitute of Atmospheric Physics (IAP) in Kühlungsborn, Germany $\left(54.1^{\circ} \mathrm{N}, 11.8^{\circ} \mathrm{E}\right)$. Three different methods of temperature measurements are applied in four altitude regions from the lower troposphere to the lower thermosphere. The potassium resonance lidar examines the Doppler broadening of the potassium $D_{1}$ resonance line generated by a tunable narrow-band laser (about $80-105 \mathrm{~km}$ altitude). The RMR lidar is used to measure the Rayleigh backscatter at a wavelength of $532 \mathrm{~nm}$, which provides an atmospheric density profile. Using the seed values from the potassium lidar, a temperature profile can be integrated from $90 \mathrm{~km}$ down to $20 \mathrm{~km}$. Because of limits in the dynamic range of the detectors, the profile is combined from two optically-separated detector channels, one detecting the backscatter signal from above $\sim 20 \mathrm{~km}$, the other measuring above $\sim 43 \mathrm{~km}$ altitude. Vibrational $\mathrm{N}_{2}$ Raman backscatter is used to determine the effect of stratospheric aerosol below about $34 \mathrm{~km}$. The rota- tional Raman backscatter in two narrow wavelength ranges provides the temperature measurements in the lower stratosphere and troposphere (up to about $23 \mathrm{~km}$ ). The different channels are combined to a single temperature profile using in each altitude bin the signal with the smallest statistical error. A detailed description of the lidar systems and methods is given by Alpers et al. (2004) with updates by Rauthe et al. (2006) and Gerding et al. (2007a).

\subsubsection{Poker Flat Research Range, Alaska lidar}

The National Institute of Information and Communications Technology (NICT) Rayleigh lidar was installed at Poker Flat Research Range, Alaska $\left(65.1^{\circ} \mathrm{N}, 147.5^{\circ} \mathrm{W}\right)$ in November 1997. This Rayleigh lidar is jointly operated by NICT and the Geophysical Institute of the University of Alaska, Fairbanks. Lidar observations of the upper stratosphere and mesosphere (e.g. 40 to $80 \mathrm{~km}$ ) are made in autumn, winter, and spring under clear sky conditions (Cutler et al., 2001; Collins et al., 2003), but are not made during the summer months owing to the elevated solar background signal. The NICT Rayleigh lidar system consists of a Nd:YAG laser, a $0.6 \mathrm{~m}$ receiving telescope with a field-of-view of $1 \mathrm{mrad}$ and optical bandwidth of $1 \mathrm{~nm}$ full-width-half-maximum (FWHM), a photomultiplier tube, a photon counting detection system, and a computer-based data acquisition system (Mizutani et al., 2000). The lidar is a fixed zenith-pointing system. The laser operates at $532 \mathrm{~nm}$ with a pulse repetition rate of $20 \mathrm{~Hz}$, the laser pulse width is $7 \mathrm{~ns}$ FWHM, and the average laser power is $10 \mathrm{~W}$. The photon counts are integrated over $0.5 \mu$ s yielding a $75 \mathrm{~m}$ range sampling resolution. The raw photon count profiles are acquired every $100 \mathrm{~s}$. The photon count profile is smoothed with a running average over $2 \mathrm{~km}$ before the measurements are further processed. The Rayleigh lidar technique assumes that the intensity profile of the scattered light is proportional to the density of the atmosphere, and the atmosphere is in hydrostatic equilibrium. The Rayleigh lidar temperature profiles are determined from the photon count profiles using standard inversion techniques (Leblanc et al., 1998). The initial temperature at the upper altitude $(\sim 80 \mathrm{~km})$ is chosen from the Extended Mass Spectrometer and ground-based Incoherent Scatter (MSISE-90) model (Hedin, 1991). The error in the temperature estimate is determined by the propagation of error from the photon count uncertainty (Wang, 2003; Nadakuditi, 2005). 


\subsubsection{Kiruna, Sweden SPIRALE flight}

SPIRALE (SPectromètre Infra Rouge pour l'étude de l'Atmosphère par diodes Laser Embarquées, a French acronym for infrared absorption spectroscopy by diode lasers) is a balloon-borne spectrometer with six tunable diode lasers dedicated to in situ measurements of trace compounds in the upper troposphere and the stratosphere up to $35 \mathrm{~km}$ altitude. Its principle and operation are given by Moreau et al. (2005). In brief, absorption of mid-infrared laser beams takes place in an open-air Herriott cell, between two mirrors separated by $3.5 \mathrm{~m}$, thus allowing a very long optical path $(430.8 \mathrm{~m})$. Vertical profiles of concentrations of a great number of species, such as $\mathrm{O}_{3}, \mathrm{CO}, \mathrm{CH}_{4}, \mathrm{~N}_{2} \mathrm{O}, \mathrm{HNO}_{3}, \mathrm{NO}_{2}$, $\mathrm{HCl}, \mathrm{HOCl}, \mathrm{H}_{2} \mathrm{O}_{2}$ and $\mathrm{COF}_{2}$ are measured with very high vertical resolution (a few meters), high sensitivity (volume mixing ratios as small as 20 pptv) and high accuracy (5 to $20 \%$ ). Since altitude-resolved volume mixing ratio profiles are retrieved using known temperature and pressure atmospheric distributions, very accurate in situ temperature measurements are required. For this purpose two temperature probes made of resistive platinum wire are deployed during the flight, at the extremities of two horizontal masts of $2.5 \mathrm{~m}$ length. The two probes are located at the opposite sides of the main axis of the sampling cell and therefore, at least one probe is thermally undisturbed by the wake of the gondola. The accuracy of the air temperature measurement is estimated to be better than $1 \mathrm{~K}$, i.e. a poor accuracy compared to the intrinsic precision of the probe itself $(0.05 \mathrm{~K})$. This poor accuracy is due to the difficulty of accounting for the thermal influence of the wire holder and other radiative effects. Pressure is also measured aboard the gondola by two calibrated and temperature-regulated capacitance manometers of $0-1034 \mathrm{hPa}$ and $0-100 \mathrm{hPa}$ full scale ranges. These sensors yield accuracies of $0.5 \mathrm{hPa}$ in the lower part of the profiles $(200 \mathrm{hPa})$ decreasing to $0.1 \mathrm{hPa}$ in the upper part $(5 \mathrm{hPa})$. This translates into an almost constant and negligible error $(<0.1 \mathrm{~K})$ on the whole temperature profile, with respect to the accuracy of the temperature sensor itself.

\subsubsection{Eureka, Canada lidar}

A DIAL (DIfferential Absorption Lidar) was operated at the Polar Environment Atmospheric Research Laboratory (PEARL - formerly Environment Canada's Arctic Stratospheric Ozone (AStrO) Observatory) in Eureka, Canada $\left(80^{\circ} \mathrm{N}, 86^{\circ} \mathrm{W}\right)$ in 2004,2005 and 2006 , obtaining measurements of ozone concentration and temperature. The Lumonics Excimer $600(\mathrm{XeCl})$ laser has a raw power of $40-50 \mathrm{~W}$ at $308 \mathrm{~nm}$. A portion of the $308 \mathrm{~nm}$ output is hydrogen Ramanshifted to $353 \mathrm{~nm}$ wavelength. The receiver, comprised of a $1.0 \mathrm{~m}$ Newtonian telescope and photomultiplier tubes, collects the Rayleigh-backscattered signal at the output wavelengths, as well as a corresponding nitrogen Raman-scattered return for the two output wavelengths $(332 \mathrm{~nm}$ from 308 and
$385 \mathrm{~nm}$ from $353 \mathrm{~nm}$ ). A more detailed description of the instrument can be found in Carswell et al. (1996).

The Rayleigh temperature profiles are calculated using the $353 \mathrm{~nm}$ returns, the Ideal Gas Law and assuming hydrostatic equilibrium as per the method described in the work of Hauchecorne and Chanin (1980) from about 30 to $70 \mathrm{~km}$ altitude. Raman vibrational scattering was used to obtain temperature from 10 to $30 \mathrm{~km}$ altitude. The $353 \mathrm{~nm}$ signal is much less sensitive to ozone absorption than the $308 \mathrm{~nm}$ channel, making it more appropriate for Rayleigh calculations. On average the uncertainty ranges from standard deviations of $1 \mathrm{~K}$ at $11 \mathrm{~km}$ decreasing to $0.2 \mathrm{~K}$ at $20-30 \mathrm{~km}$ and then increasing to $35 \mathrm{~K}$ at $70 \mathrm{~km}$.

\subsubsection{Eureka, Canada radiosondes}

Vaisala radiosondes RS80 and RS92 (Nash and Schmidlin, 1987; Ivanov et al., 1991) are meteorological instruments used by Environment Canada, who provides the radiosonde ascent data consisting of pressure, temperature, humidity, wind speed and wind direction (and occasionally other quantities such as ozone). Radiosondes are launched operationally from the Eureka Weather Station $\left(79.98^{\circ} \mathrm{N}\right.$, $85.93^{\circ} \mathrm{W}$ ) at 11:15 and 23:15 UT each day. Measurements are taken with a sonde suspended from a hydrogen-filled balloon which travels with an average ascent speed of about $5 \mathrm{~m} / \mathrm{s}$ to an altitude of about $30 \mathrm{~km}$. The measurements are transmitted to the ground and recorded with $10 \mathrm{~s}$ temporal resolution, which leads to a vertical resolution of about $50 \mathrm{~m}$. The radiosonde data are interpolated to the ACE-FTS $1 \mathrm{~km}$ data grid and smoothed with a triangular weighting function of width $4 \mathrm{~km}$. This ensures that the radiosonde temperature data have approximately the same vertical resoluton as the ACE-FTS temperature measurements.

\subsubsection{Radiosondes and lidars from the GAW and NDACC ground-based networks}

In addition to the radiosondes and lidars listed in the sections above, we have used radiosonde and lidar measurements obtained by ground-based observation networks in our comparisons. These measurements are archived in the Network for the Detection of Atmospheric Composition Change (NDACC, formerly the NDSC) database and the World Meteorological Organization's (WMO's) World Ozone and UV Data Center (WOUDC), two major components of WMO's Global Atmospheric Watch programme (GAW).

The balloon-borne radiosondes operating during ozonesonde flights were used in these comparisons. These flights measured the vertical profile of pressure and temperature from the ground up to $30 \mathrm{~km}$ with a typical vertical resolution of $100-150 \mathrm{~m}$. The majority of the ground-based stations in the GAW and NDACC network used Vaisala sondes that were equipped with a high precision and accuracy temperature sensor. These temperature sensors 
Table 1. List of GAW and NDACC ground-based stations used in this study.

\begin{tabular}{|c|c|c|c|c|}
\hline \multicolumn{5}{|c|}{ RADIOSONDES } \\
\hline Station & Location & Latitude & Longitude & Institute \\
\hline Alert & Canada & 82.50 & -62.33 & MSC \\
\hline Eureka & Canada & 80.05 & -86.42 & MSC \\
\hline Ny-Alesund & Svalbard & 78.91 & 11.88 & AWI \\
\hline Thule & Greenland & 76.51 & -68.76 & DMI \\
\hline Resolute & Canada & 74.72 & -94.98 & MSC \\
\hline Summit & Greenland & 72.60 & -38.50 & NOAA \\
\hline Scoresbysund & Greenland & 70.48 & -21.97 & DMI \\
\hline Sodankylä & Finland & 67.37 & 26.67 & FMI \\
\hline Keflavik & Iceland & 63.97 & -22.60 & INTA \\
\hline Orlandet & Norway & 63.42 & 9.24 & NILU \\
\hline Jokioinen & Finland & 60.82 & 23.48 & FMI \\
\hline Churchill & Canada & 58.75 & -94.07 & MSC \\
\hline Legionowo & Poland & 52.40 & 20.97 & INWM \\
\hline De Bilt & Netherlands & 52.10 & 5.18 & KNMI \\
\hline Uccle & Belgium & 50.80 & 4.35 & KMI \\
\hline Bratts Lake & Canada & 50.20 & -104.72 & MSC \\
\hline Hohenpeißenberg & Germany & 47.80 & 11.02 & DWD \\
\hline Payerne & Swiss Alps & 46.49 & 6.57 & $\mathrm{MCH}$ \\
\hline Egbert & Canada & 44.23 & -79.78 & MSC \\
\hline Haute Provence & French Alps & 43.94 & 5.71 & CNRS \\
\hline Yarmouth & Canada & 43.87 & $-6-6.10$ & MSC \\
\hline Sapporo & Japan & 43.06 & 141.33 & JMA \\
\hline Madrid & Spain & 40.46 & -3.65 & INME \\
\hline Boulder & USA & 40.03 & -105.25 & NOAA \\
\hline Tsukuba & Japan & 36.05 & 140.13 & JMA \\
\hline Marambio & Antarctica & -64.28 & -56.72 & FMI/INTA \\
\hline Dumont d'Urville & Antarctica & -66.67 & 140.01 & CNRS \\
\hline Syowa & Antarctica & -69.00 & 39.58 & JMA \\
\hline Neumayer & Antarctica & -70.65 & -8.25 & AWI \\
\hline McMurdo & Antarctica & -77.85 & 166.67 & UWYO \\
\hline Belgrano & Antarctica & -77.87 & -34.63 & INTA \\
\hline \multicolumn{5}{|c|}{ LIDARS } \\
\hline Station & Location & Latitude & Longitude & Institute \\
\hline Hohenpeißenberg & Germany & 47.80 & 11.02 & DWD \\
\hline Haute Provence & French Alps & 43.94 & 5.71 & CNRS \\
\hline Table Mountain & California & 34.23 & 117.41 & JPL \\
\hline
\end{tabular}

are designed to work optimally in the $-90^{\circ} \mathrm{C}$ to $60^{\circ} \mathrm{C}$ range, with a typical accuracy of $0.5 \mathrm{~K}$ (Antikainen et al., 2002; da Silveira et al., 2003; Nash et al., 2006). As described earlier in this section, Rayleigh lidar systems provide the vertical profiles of temperature between 30 and $70 \mathrm{~km}$ during night using the Rayleigh-scattering technique. The standard output of the lidar systems is a mean temperature profile per night, with a vertical resolution of $3 \mathrm{~km}$, integrated over non-cloudy times. The Rayleigh lidar systems reach an accuracy of $1 \mathrm{~K}$ in the $35-65 \mathrm{~km}$ altitude range. We have selected available correlative data that offer a sufficient coincidence with ACE-FTS measurements using 31 sonde stations and 3 temperature lidars (Table 1). These stations form a robust set of independent correlative measurements of well-known quality (Keckhut et al., 2004). The coincidences are essentially located at high and middle latitudes where the majority of the ACE measurements occur.

\section{Comparisons with ACE-FTS temperatures}

Validation of a satellite sensor is an exercise in compromise, particularly for an occultation instrument with limited geographical sampling (as is the situation here). It is virtually impossible for an ACE-FTS measurement and the validating measurement to be in the same place at the same time. As in all validation studies, we tried to achieve a balance between spatial-temporal proximity and ensuring an adequate sample size to provide decent statistics (and to reduce the effects of geophysical variability on the comparisons). The coincidence criteria used in generating the comparisons varied from instrument to instrument, as described below. These criteria were selected in each case to make best use of the overlap between data sets.

When considering the proximity of measurements for validation studies, a short discussion of horizontal resolution and measurement location is needed to elucidate the underlying assumptions implied by the word "coincidence" as used in this study. The horizontal resolution of a measurement varies greatly between the instruments used herein. As mentioned in Sect. 1, a satellite measurement using a limb-viewing geometry (such as an ACE-FTS occultation measurement) has a path length of approximately $500 \mathrm{~km}$ through the atmosphere and thus each profile point is an average over this horizontal distance. In contrast, lidar measurements or in situ balloon measurements (such as radiosondes or SPIRALE) have much greater horizontal resolution and therefore are much more sensitive to local atmospheric structures. To find coincident measurements for comparisons, a location has to be assigned to each observation. For lidar observations, the measurement occurs at the location of the instrument. Radiosondes typically travel no more than $50-100 \mathrm{~km}$ from the launch site so for these comparisons the location of the measurement has been taken to be the same as the launch site. The coincidence criteria are more challenging for satellite observations (such as those made by ACE-FTS) because the satellite is moving along its orbit while it is making a measurement and thus, the profile measurement does not occur over a single point on Earth. The ground track can cover several hundred $\mathrm{km}$, so the location of a representative altitude has been used to identify the location of each occultation. For these comparisons, the latitude, longitude and time of the $30 \mathrm{~km}$ tangent point (calculated geometrically) was used as the location of the ACE-FTS occultation.

\subsection{SABER}

To compare ACE-FTS and TIMED/SABER temperature profiles, the following coincidence criteria are adopted: $200 \mathrm{~km}$ or less in distance and $3 \mathrm{~h}$ or less in time. Data from 1 March 2004-31 August 2006 are used in these comparisons. As shown by Petelina et al. (2005), such tight coincidence criteria are necessary, particularly at mesospheric altitudes, where the spatial and temporal variability in the atmospheric 
temperature field is significant (Sica et al., 2002). Examples of individual coincident ACE-FTS and SABER temperature profiles are shown in Fig. 1. As data from these two instruments are provided on different altitude grids, SABER profiles have been interpolated onto the ACE-FTS 1-km grid using cubic splines. Note that while individual profiles in Fig. 1 are shown for altitudes $11.5-100.5 \mathrm{~km}$, the statistical analysis, as mentioned earlier, is restricted to the $11.5-70.5 \mathrm{~km}$ range where SABER temperature retrievals agree well with other data sets.

Fig. 1 (11 May 2005) shows that below $70 \mathrm{~km}$ good agreement between the instruments, within $2-5 \mathrm{~K}$ is found. Fig. 1 also shows an example on 14 August 2005 where the ACEFTS version 2.2 profile (in red) exhibits unphysical oscillations in the mesosphere and thermosphere. Note that the high-frequency fluctuations in the residual profile (ACESABER) arise from these unphysical oscillations, while the broader structure in the residual profile is a consequence of geophysical differences between the two measurements. The cause of unphysical oscillations in ACE-FTS version 2.2 temperature profiles (along with the improvements implemented in the next generation ACE-FTS processing version) will be discussed in Sect. 4 .

A summary of the monthly number of ACE-FTS and SABER coincidences and corresponding latitude ranges is given in Table 2 for the time period March 2004 through August 2006. The last column of the table shows the number of occultations in the group that were judged to contain unphysical oscillations. Problem occulations tend to occur in clusters, a consequence of the slow change in measurement conditions from occultation to occultation. It is therefore worth noting that for months with 20 or more coincidences, profiles with oscillations represent less than $25 \%$ of the total. Globally, the number of occultations in this data set (for all years and all months) containing unphysical oscillations represents about $10 \%$ of the total.

In a preliminary version of the next generation ACE-FTS processing (to be called version 3.0), the unphysical oscillations observed in the version 2.2 data set are removed. In a few cases, real structure in the mesosphere (judging from the SABER results) is suppressed in the preliminary version 3.0 results, a consequence of marginal sampling of the structure with the ACE-FTS measurements.

Mean differences and standard deviations for coincident ACE-FTS and SABER measurements are shown in Fig. 2 for a selected set of months. When considering all comparisons below $45 \mathrm{~km}$, the ACE-FTS and SABER data agree to within $1-2 \mathrm{~K}$ most of the time. The standard deviation range at these altitudes is also smallest. In March 2004, May 2005, and May 2006, differences between the two instruments below $15 \mathrm{~km}$ reached $3-4 \mathrm{~K}$ with ACE-FTS being larger than SABER. A number of the plots in Fig. 2 exhibit a "bump" in the comparisons near $23 \mathrm{~km}$, with the ACE-FTS temperatures about $2 \mathrm{~K}$ lower than the SABER temperatures. For altitudes above about $50 \mathrm{~km}$, there is a systematic $2-3 \mathrm{~K}$ high
Table 2. Latitude range and number of coincidences with SABER for ACE-FTS sunset (ss) and sunrise (sr) occultations including number of occultations exhibiting unphysical oscillations in the mesosphere and thermosphere.

\begin{tabular}{|c|c|c|c|c|}
\hline Month & Mode & $\begin{array}{l}\text { Latitude } \\
\text { Range }\end{array}$ & \# Coincidences & $\begin{array}{l}\text { \# of Unphysical } \\
\text { Oscillations }\end{array}$ \\
\hline \multicolumn{5}{|c|}{2004} \\
\hline 3 & ss & $75-80 \mathrm{~N}$ & 68 & 4 \\
\hline 5 & $\mathrm{sr}$ & $59-69 \mathrm{~N}$ & 9 & 1 \\
\hline 5 & ss & $63-65 \mathrm{~S}$ & 36 & 9 \\
\hline 6 & ss & $49-54 N$ & 11 & 4 \\
\hline 7 & $\mathrm{sr}$ & $63-65 \mathrm{~S}$ & 37 & 8 \\
\hline 7 & ss & $66-68 \mathrm{~N}$ & 12 & 0 \\
\hline 8 & $\mathrm{sr}$ & $62-65 \mathrm{~S}$ & 12 & 6 \\
\hline 9 & $\mathrm{sr}$ & $82-83 \mathrm{~N}$ & 14 & 1 \\
\hline 9 & ss & $73-79 \mathrm{~S}$ & 25 & 6 \\
\hline 11 & $\mathrm{sr}$ & $66-70 \mathrm{~S}$ & 35 & 1 \\
\hline 11 & ss & $68-70 \mathrm{~N}$ & 30 & 5 \\
\hline 12 & $\mathrm{sr}$ & $43-46 \mathrm{~S}$ & 5 & 2 \\
\hline \multicolumn{5}{|c|}{2005} \\
\hline 1 & $\mathrm{sr}$ & $65-66 \mathrm{~N}$ & 19 & 1 \\
\hline 1 & ss & $63-68 \mathrm{~S}$ & 15 & 2 \\
\hline 2 & $\mathrm{sr}$ & $55-66 \mathrm{~N}$ & 6 & 3 \\
\hline 3 & $\mathrm{sr}$ & $78-83 \mathrm{~S}$ & 109 & 0 \\
\hline 3 & ss & $75-80 N$ & 65 & 1 \\
\hline 5 & $\mathrm{sr}$ & $55-70 \mathrm{~N}$ & 35 & 5 \\
\hline 5 & ss & $64-67 \mathrm{~S}$ & 49 & 9 \\
\hline 7 & $\mathrm{sr}$ & $62-64 \mathrm{~S}$ & 40 & 4 \\
\hline 7 & ss & $53-68 \mathrm{~N}$ & 29 & 3 \\
\hline 8 & $\mathrm{sr}$ & $35-64 \mathrm{~S}$ & 16 & 5 \\
\hline 9 & $\mathrm{sr}$ & $77-83 \mathrm{~N}$ & 69 & 3 \\
\hline 9 & ss & $73-80 \mathrm{~S}$ & 74 & 4 \\
\hline 10 & ss & $70-71 \mathrm{~N}$ & 4 & 1 \\
\hline 11 & $\mathrm{sr}$ & $66-70 \mathrm{~S}$ & 22 & 1 \\
\hline 11 & ss & $67-71 \mathrm{~N}$ & 56 & 4 \\
\hline 12 & $\mathrm{sr}$ & $39-48 \mathrm{~S}$ & 4 & 0 \\
\hline \multicolumn{5}{|c|}{2006} \\
\hline 1 & ss & $63-68 \mathrm{~S}$ & 22 & 1 \\
\hline 2 & $\mathrm{sr}$ & $55-59 \mathrm{~N}$ & 7 & 2 \\
\hline 3 & $\mathrm{sr}$ & $77-83 \mathrm{~S}$ & 47 & 1 \\
\hline 5 & $\mathrm{sr}$ & $59-69 \mathrm{~N}$ & 28 & 2 \\
\hline 5 & ss & $63-65 \mathrm{~S}$ & 16 & 0 \\
\hline 7 & $\mathrm{sr}$ & $63-65 \mathrm{~S}$ & 27 & 3 \\
\hline 7 & ss & $49-68 \mathrm{~N}$ & 12 & 1 \\
\hline 8 & $\mathrm{sr}$ & $65-66 \mathrm{~S}$ & 5 & 3 \\
\hline
\end{tabular}

bias of the ACE-FTS temperatures relative to SABER. This effect does not seem to have any seasonal or latitudinal dependence.

In a companion paper in this issue, individual comparisons of ACE-FTS and SABER temperatures are given by Manney et al. (2007), who show comparisons of individual ACEFTS and SABER coincident profile pairs, as well as dailyaveraged ACE-FTS, coincident MLS and SABER profiles. 

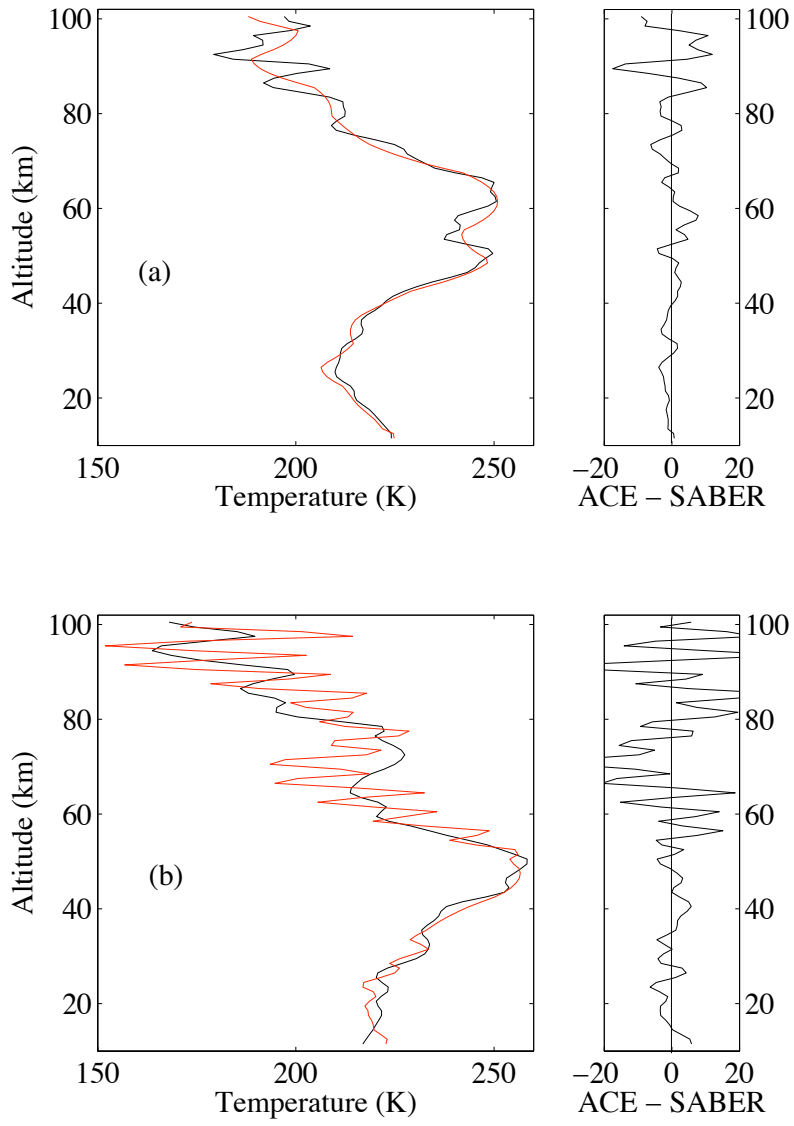

Fig. 1. Typical examples of individual temperature profiles (left panels) for SABER v1.06 (black curve) and ACE-FTS v2.2 (red curve) and temperature differences (in $\mathrm{K}$ - right panels). As noted in the text, the oscillations in the ACE temperatures are not geophysical variations. (a) ACE-FTS occultation on 11 May 2005 at 01:40:59 UT $\left(66.29^{\circ} \mathrm{S}, 163.41^{\circ} \mathrm{W}\right)$ compared to SABER at 01:49:23 UT $\left(65.78^{\circ} \mathrm{S}, 160.48^{\circ} \mathrm{W}\right)$. (b) ACE occultation on $14 \mathrm{Au}-$ gust 2005 at $15: 44: 16\left(42.22^{\circ} \mathrm{S}, 21.80^{\circ} \mathrm{E}\right)$ compared to SABER at 18:20:45 UT $\left(42.36^{\circ} \mathrm{S}, 22.39^{\circ} \mathrm{E}\right)$.

\subsection{MIPAS}

MIPAS v4.62 temperature data are compared with ACE-FTS version 2.2 data for the period from 21 February 2004 to 26 March 2004. During the first five months of the ACE mission only sunsets were measured because of issues with spacecraft pointing at sunrise. Therefore the latitude coverage available for this comparison is limited to $20^{\circ} \mathrm{N}$ to $90^{\circ} \mathrm{N}$.

Further limiting the comparisons of profile locations to $6 \mathrm{~h}$ time difference and $300 \mathrm{~km}$ horizontal difference produces regular matches in the $80^{\circ} \mathrm{N}$ to $90^{\circ} \mathrm{N}$ latitude region. The slightly relaxed temporal criterion has been chosen in order to increase the statistics of the comparison, which includes 137 coincident pairs. For each of the selected pairs, the MIPAS temperature profiles were interpolated on the pressure
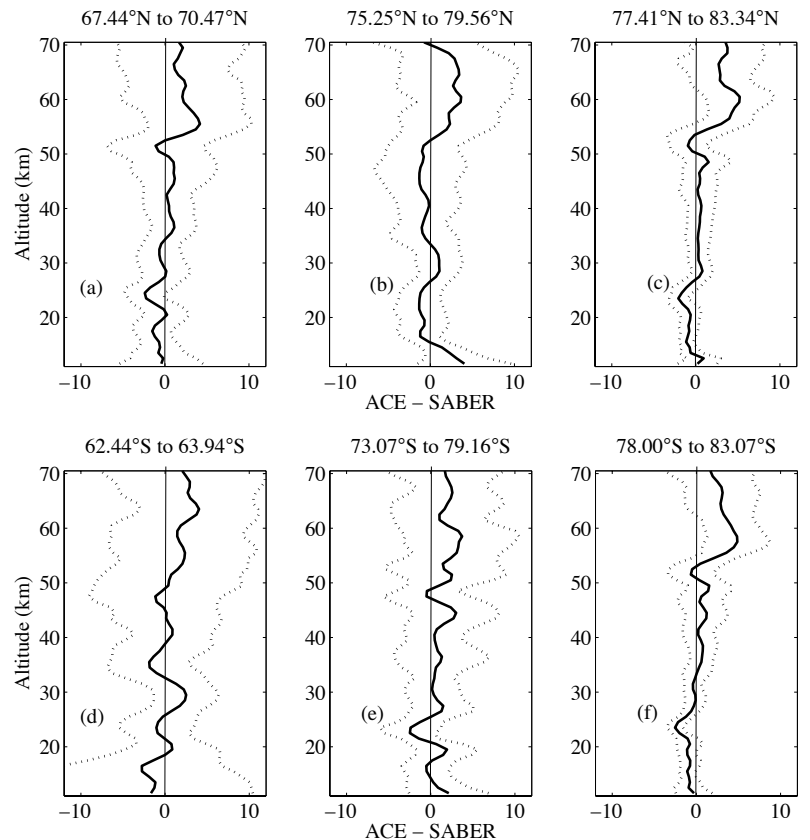

Fig. 2. Mean temperature differences (in $\mathrm{K}$ ) between coincident ACE-FTS v2.2 and SABER v1.06 temperature profiles for sunset (ss) and sunrise (sr) occultations (thick black lines) for selected cases in the Northern (top panels) and Southern (bottom panels) Hemispheres. Thin dashed lines indicate the standard deviations of the differences (a) November 2005 (56 ss coincidences), (b) March 2004 (56 ss coincidences), (c) September 2005 (69 sr coincidences), (d) July 2005 (40 sr coincidences), (e) September 2004 (25 ss coincidences), and (f) March 2005 (109 sr coincidences). Related parameters, such as the ACE-FTS sunset/sunrise occultation, latitude range, and number of coincidences, are given in Table 2 .

grid corresponding to the $1 \mathrm{~km}$ altitude grid of the ACE-FTS data. This was done to enable a statistical analysis of collocated measurements having different vertical spacing. The interpolated profiles are used to calculate the differences in temperature values retrieved by ACE-FTS and by MIPAS.

Figure 3 shows the mean temperature profiles and differences for MIPAS v4.62 (black) and ACE-FTS v2.2 (red) for the latitude region $80^{\circ} \mathrm{N}$ to $90^{\circ} \mathrm{N}$. MIPAS includes only daytime profiles. Differences between the two instruments are within $2-4 \mathrm{~K}$ at all altitudes. There is a small negative bias of the ACE-FTS temperatures relative to the MIPAS temperatures below about $45 \mathrm{~km}$, and there is a small positive bias above $45 \mathrm{~km}$.

\subsection{HALOE}

The coincidence criteria used for the HALOE instrument were $500 \mathrm{~km}$ in horizontal distance and $4 \mathrm{~h}$ in time. These criteria provide a total of 53 coincidences: 33 in July 2004 in the latitude range $64-68^{\circ} \mathrm{N}$, five in September 2004 near 


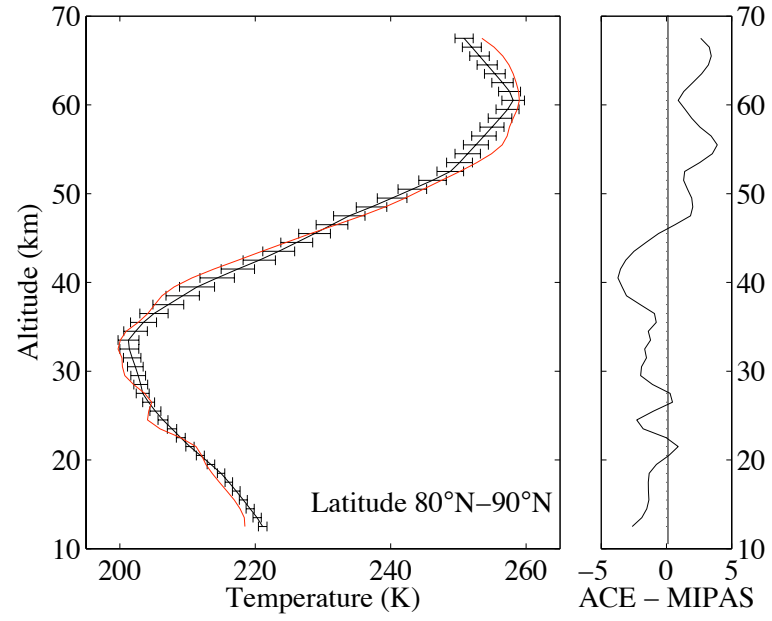

Fig. 3. Mean temperature profiles from MIPAS v4.62 (black) and ACE-FTS v2.2 (red) for the latitude region $80^{\circ} \mathrm{N}$ to $90^{\circ} \mathrm{N}$ (left panel) and temperature difference (in $\mathrm{K}$ - shown in right panel). Error bars indicate the standard deviation of the mean of the MIPAS temperatures.

latitude $60^{\circ} \mathrm{N}, 12$ in January 2005 in the latitude range 63 to $68^{\circ} \mathrm{S}$, and three coincidences in August 2005 near $50^{\circ} \mathrm{S}$. A few coincidences from January and February 2004 were excluded from the comparisons because of quality issues with ACE measurements early in the mission. HALOE measurements were interpolated onto the ACE-FTS standard 1-km grid using a cubic spline.

The results of the comparison between HALOE and ACEFTS temperatures are shown in Fig. 4. The top panel of the figure shows the average differences for all 53 coincidences. Below $\sim 70 \mathrm{~km}$, the agreement is good, within $2-4 \mathrm{~K}$. Above $70 \mathrm{~km}$, the discrepancies grow quite large. As noted in McHugh et al. (2005), the HALOE temperature retrieval suffers in accuracy in this altitude region in the presence of polar mesospheric clouds (PMCs). The majority of the coincidences between the two instruments occur in a location and season where one expects PMC formation. Only eight of the coincidences are not at risk of PMC effects in the HALOE temperature retrievals: the five coincidences in September 2004, and the three coincidences in August 2005. The lower portion of the figure shows the comparison using only these eight coincidences. With fewer measurements to average out geophysical variability, the portion of the curve below $70 \mathrm{~km}$ is somewhat noisier but still within $2-4 \mathrm{~K}$. The differences above $70 \mathrm{~km}$ are dramatically improved compared to the results for the full data set, consistent with the assumption of PMC contamination in HALOE temperature retrievals. In the comparison with the reduced data set, the ACE-FTS temperatures show a systematic hot bias of 5-6 K above $70 \mathrm{~km}$.
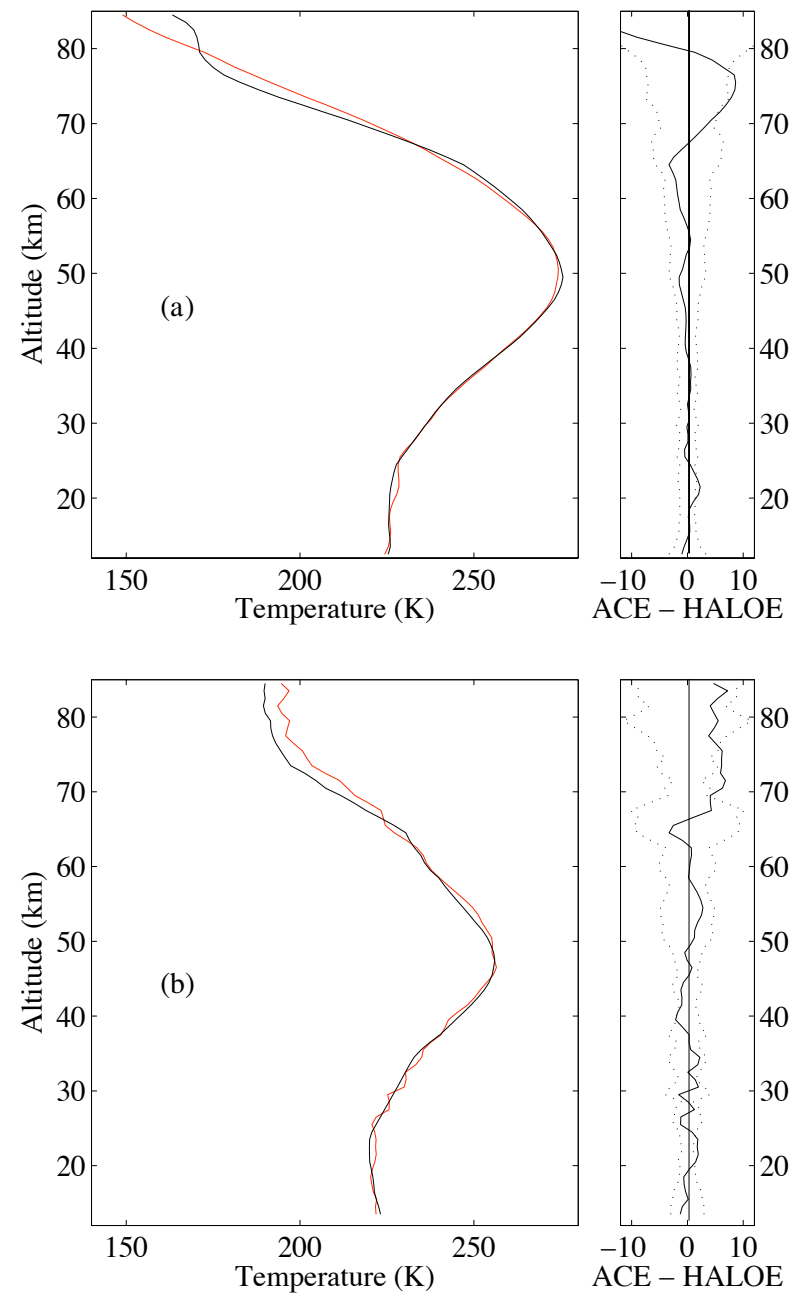

Fig. 4. Mean temperature profiles (left panels) for HALOE v19 (black) and ACE-FTS v2.2 (red) and temperature differences (in $\mathrm{K}$, right panels in solid black lines) with standard deviation of the differences (dotted black lines). (a) Results for all 53 coincidences, measurements within $500 \mathrm{~km}$ and $4 \mathrm{~h}$. (b) Results from the subset of eight coincidences without the risk of PMC contamination on the HALOE temperature retrievals.

\subsection{Davis, Antarctica Rayleigh-scatter lidar}

In determining which ACE-FTS events to compare with, the following criteria were used. Only lidar data collected with the new telescope system were used for the Davis Lidar, which restricted comparisons to after late February 2005. ACE-FTS measurements must be within a $600 \mathrm{~km}$ radius of Davis and available within $6 \mathrm{~h}$ of the start or end of a lidar observing session. These restrictions decreased the possible comparison opportunities to 11 . This number only marginally changed if the time or range restrictions were eased (e.g., to $1000 \mathrm{~km}$ radius or $12 \mathrm{~h}$ in time). The small 

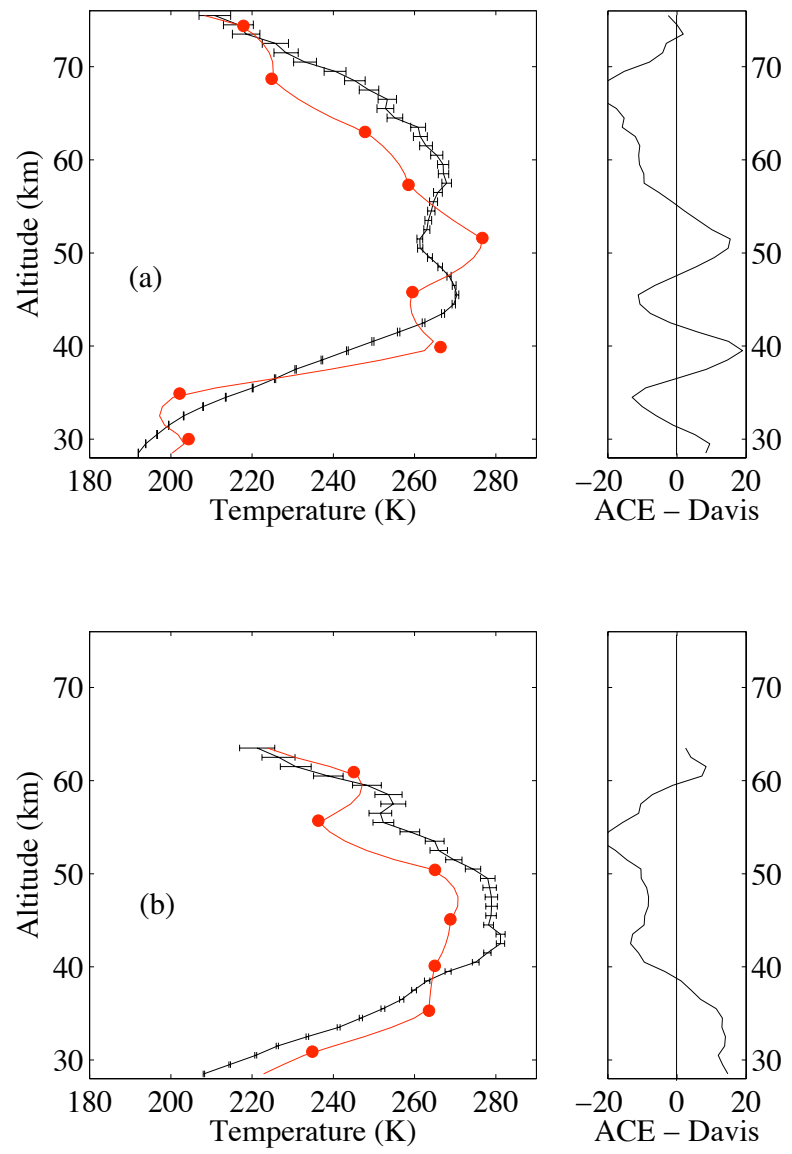

Fig. 5. Examples of the highly structured temperature field present in the Antarctic stratosphere. While both 28 July 2006 (a) and 30 July 2005 (b) show the same general features between the two instruments, there are significant offsets in height. In the left panel, ACE-FTS v2.2 temperature profiles are shown by red lines (for the interpolated $1 \mathrm{~km}$ grid) and by solid red circles (for measurement grid results) and comparison instrument temperature profiles are shown by black lines. The error bars in the left panel are $\pm 1 \sigma$ standard deviation of the comparison instrument's statistical error. In the right panel, temperature difference between the profiles is shown (in K).

number is a direct consequence of the geometry of the satellite measurements, which restricts the time of year when measurements are possible near Davis, and the fact that the lidar is only operated in fair weather conditions.

As an example of our comparisons, we consider the comparison for ACE-FTS event sr15919 (Fig. 5). The ACE-FTS measurement was acquired approximately $500 \mathrm{~km}$ northeast of Davis at 03:40 UT on 28 July 2006. Lidar observations were conducted between 12:45 UT on 27 July and 01:19 UT on 28 July. The temperature field from the Atmospheric InfraRed Sounder (AIRS) on the Aqua satellite at $1 \mathrm{hPa}$ in the vicinity of Davis during the lidar measurements was used to investigate spatial variations (Gettelman et al., 2004). Temperature variations of up to $\sim 15 \mathrm{~K}$ are apparent, with a general NW-SE gradient. The AIRS data show that horizontal temperature gradients of at least $5 \mathrm{~K}$ over a distance of $500 \mathrm{~km}$ can occur in the mid-stratosphere at this location. This scale of variability dominates over the measurement uncertainties for the $2 \mathrm{~h}$ resolution lidar retrievals at this altitude. A second example of this variability is shown in Fig. 5 for 30 July 2005. Note the geophysical variability in each of these cases is greater than the statistical errors of the measurements, supporting our argument that large horizontal spatial temperature gradients exist.

During the winter and spring, Davis lies near the edge of the stratospheric polar vortex, and the vertical temperature profile, particularly in the stratosphere, can show relatively large meridional, zonal and vertical gradients due to dynamical effects related to the origin of the air (from inside or outside the vortex), planetary waves and gravity waves. In the summer, the stratosphere and mesosphere have generally less spatial and temporal variability compared to the winter. Comparisons with satellite temperature measurements from other instruments with closer spatial proximity to the Davis lidar show in general closer agreement than shown in Fig. 5 (Klekociuk et al., 2003).

\subsection{Davis, Antarctica scanning spectrometer}

Nightly averaged $\mathrm{OH}(6-2)$ rotational temperatures in the mesopause region above Davis station, Antarctica have been compared with ACE-FTS v2.2 temperatures. Of the 94 available occultations found within a $500 \mathrm{~km}$ radius of Davis, 57 had coincident nightly-averaged-hydroxyl-rotational temperatures (Fig. 6). Nocturnal hydroxyl measurements are limited to the period between mid-February and the end of October at the latitude of Davis. The maximum nightly observing time is about $19 \mathrm{~h}$ over mid-winter. Hydroxyl emissions typically originate in a layer centred near $87 \mathrm{~km}$ altitude and spanning about $8 \mathrm{~km}$. In Fig. 6, hydroxyl temperatures are compared with the ACE-FTS $87.5 \mathrm{~km}$ grid point.

Of the 57 samples, the closest range separation is $126 \mathrm{~km}$ (average $361 \mathrm{~km}$ ) and the nearest time difference from the $\mathrm{OH}$ nightly mean observing time is $4 \mathrm{hrs} 40 \mathrm{~min}$ (average $9 \mathrm{~h} 10 \mathrm{~min})$. Considerable atmospheric temperature variability would be expected on these spatial and temporal scales. Nevertheless, for the 57 comparisons considered, $\mathrm{OH}$ temperatures were on average 5-7 K warmer than ACEFTS measurements. The mean and standard deviation for the $\mathrm{OH}$ temperatures is $203.0 \pm 5.8 \mathrm{~K}$ compared to ACEFTS v2.2 at $87.5 \mathrm{~km}$, which is $196.3 \pm 10.9 \mathrm{~K}$. If the ACEFTS temperatures are weighted with a Gaussian centered on $87 \mathrm{~km}$ with a half width of $8 \mathrm{~km}$ using grid points from $73.5 \mathrm{~km}$ to $100.5 \mathrm{~km}$, the mean and standard deviation becomes $196.6 \pm 7.8 \mathrm{~K}$, slightly closer to the $\mathrm{OH}$-derived temperatures. 
Using the Langhoff et al. (1986) transition probabilities increase the temperatures $2 \mathrm{~K}$ relative to other sets of transition probabilities available. Given that the calibration uncertainty in these measurements is of the order of $0.3 \mathrm{~K}$, the agreement between the Davis OH and ACE-FTS averages including both these factors is about $5 \mathrm{~K}$. This result is reasonable considering the geophysical spatial and temporal variability and the assumption of a typical (e.g. single humped) $\mathrm{OH}$ layer at $87 \mathrm{~km}$ altitude.

\subsection{London, Canada lidar}

Temperature retrievals from seven ACE-FTS measurements within $1000 \mathrm{~km}$ of the Purple Crow Lidar were compared with PCL temperature measurements for the entire night, both to compare any bias between the temperatures and to estimate retrieval error for ACE-FTS using the high temporal resolution of the PCL. The PCL data was linearly interpolated onto the ACE-FTS measurement grid. Figure 7 shows examples of the agreement between the two instruments, highlighting the unphysical oscillations which can occur in the ACE-FTS v2.2 temperatures and the effect of a smallscale mesospheric inversion, which ACE-FTS can not resolve. On 1 September 2005, the agreement between the two instruments is good, particularly in the lower mesosphere. However, above $70 \mathrm{~km}$, the PCL measures a moderate temperature inversion, probably due to the interaction between tides and smaller-scale waves (e.g. Sica et al., 2002), which the ACE-FTS can not resolve. On 5 May 2006, the agreement is again good between the two instruments until above $65 \mathrm{~km}$, where unphysical oscillations occur in the ACE-FTS measurements (see Sect. 4). The difference plots show the distance between the oscillations in the lower panel is on the order of the vertical spacing of the ACE-FTS measurements, characteristic of the unphysical oscillations, as opposed to the inversion structure observed in the top panel which is present over 5 ACE-FTS measurement points.

For the seven coincidences available, the ACE-FTS temperatures have a bias towards higher temperatures than the PCL temperatures. The ACE-FTS temperature measurements are on average $5.5 \pm 1.8 \mathrm{~K}$ hotter than the PCL.

As mentioned previously, the ACE-FTS pressure/temperature retrieval routine is divided into two altitude regions. As described in Boone et al. (2005), there is a transition in the fundamental retrieval philosophy at the third measurement point above $43 \mathrm{~km}$ (typically between 50 to $60 \mathrm{~km}$ ). We therefore consider separately the temperature bias in the two altitude regions. The low altitude region, taken as the altitude of the lowest PCL Rayleigh-scatter measurement $(28 \mathrm{~km})$ up to $60 \mathrm{~km}$, shows no bias within the uncertainty $(0.3 \pm 1.5 \mathrm{~K})$. The high altitude region (taken as 60 to $95 \mathrm{~km}$ ) has a bias of $5.9 \pm 2.1 \mathrm{~K}$.

This calculation was repeated incorporating PCL Vibrational-Raman Scattering measurements (Argall et al., 2007). These measurements extend the comparison down-
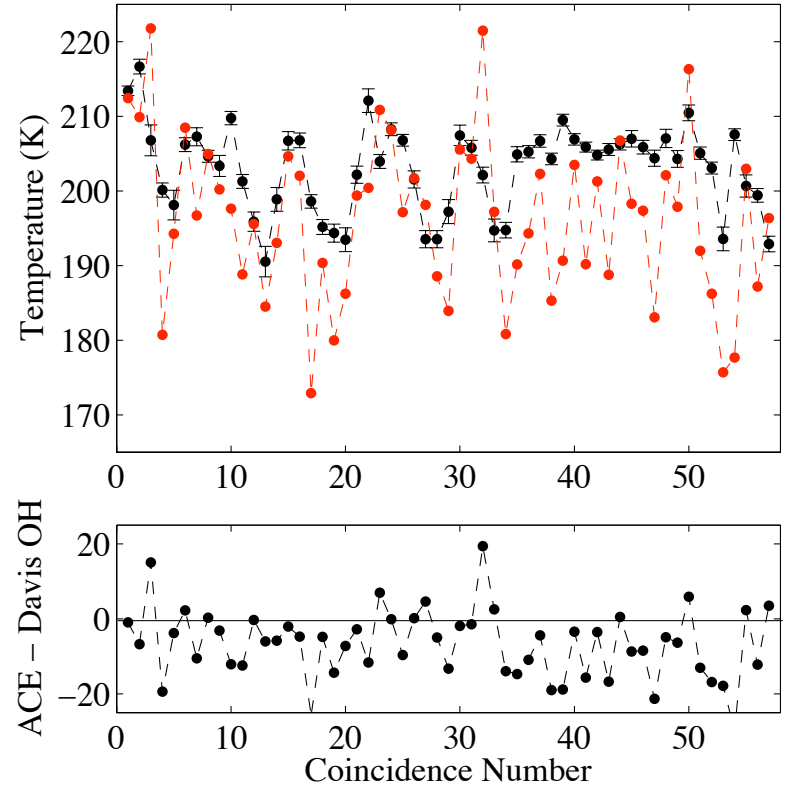

Fig. 6. A comparison of 57 coincident Davis $\mathrm{OH}$ rotational temperatures (black) with ACE-FTS v2.2 temperatures (red) at $87.5 \mathrm{~km}$ altitude (top) and differences (bottom; in K). The error bars on the $\mathrm{OH}$ rotational temperature time series are $1-\sigma$ standard deviation in the nightly mean.

wards to $12 \mathrm{~km}$. Three additional coincident data sets also became available for this analysis ( 29 and 30 June 2005, and 5 May 2006). These results were comparable: an apparent bias of $5.4 \pm 2.0 \mathrm{~K}$ at high altitudes, and no detectable bias at low altitudes $(0.4 \pm 1.6 \mathrm{~K})$. In preliminary comparisons with results from the next generation of ACE-FTS processing software (the so-called "preliminary version 3.0") with both the PCL Rayleigh Scattering and Vibrational-Raman Scattering results, there is no indication of a temperature bias (e.g. $<0.5 \mathrm{~K})$ in any altitude region.

At present, the ACE-FTS temperature retrieval algorithm does not generate error estimates from the pressure/temperature fitting procedure. This omission is due to the computational difficulties involved in propagating errors through the modified global fitting routine used in the ACEFTS retrievals. Retrieval quantities are correlated. In the forward model calculation, errors in temperature can be compensated for through changes in associated pressure or tangent height, making it difficult to isolate a meaningful error estimate on a particular retrieval parameter.

To estimate the ACE-FTS contribution to the error, the geophysical and statistical errors as determined from the PCL measurements were calculated and subtracted in quadrature from the total variance as follows. The PCL statistical errors are determined by the photon counting statistics of the lidar measurements (Measures, 1984). Geophysical variability 

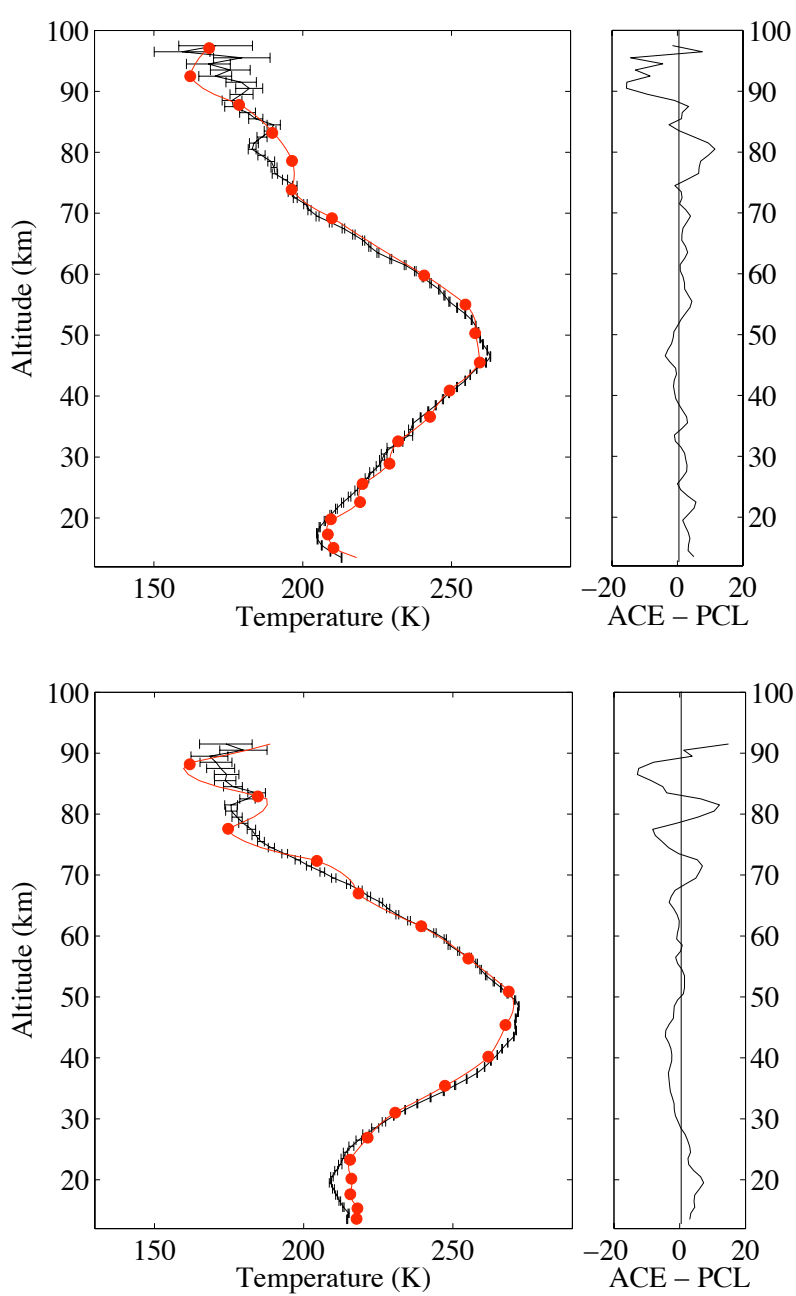

Fig. 7. Sample comparisons showing generally good agreement (in K) between the Purple Crow Lidar (black) and ACE-FTS v2.2 (red) temperatures on 1 September 2005 (top). In this case, ACE-FTS misses a small-scale mesospheric inversion. Comparison on 5 May 2006 (bottom), with the unphysical oscillations in the ACE-FTS v2.2 temperatures clearly visible. The agreement between the instruments is particularly good in the mesosphere up to $65 \mathrm{~km}$ on this night where no clear inversion is present.

was estimated by calculating the RMS variation in the PCL measurements spaced by 30 min intervals over the night's observations. The ACE-FTS statistical error $\left(\sigma_{\text {FTS }}\right)$ can then be estimated from the total error as follows:

$\sigma_{\mathrm{FTS}}=\sqrt{\left(T_{\mathrm{PCL}}-T_{\mathrm{FTS}}\right)^{2}-\sigma_{\mathrm{PCL}}^{2}-\sigma_{\mathrm{geo}}^{2}}$

In the comparisons with the PCL Rayleigh lidar measurements, the bias of $5.9 \mathrm{~K}$ calculated previously was subtracted from the high altitude ACE-FTS data. Calculating the random error using Eq. (1) on these modified ACE-FTS data, the value obtained (averaged over all altitudes and measurement dates) was $\pm 2.1 \mathrm{~K}$. Incorporating the PCL Vibrational-
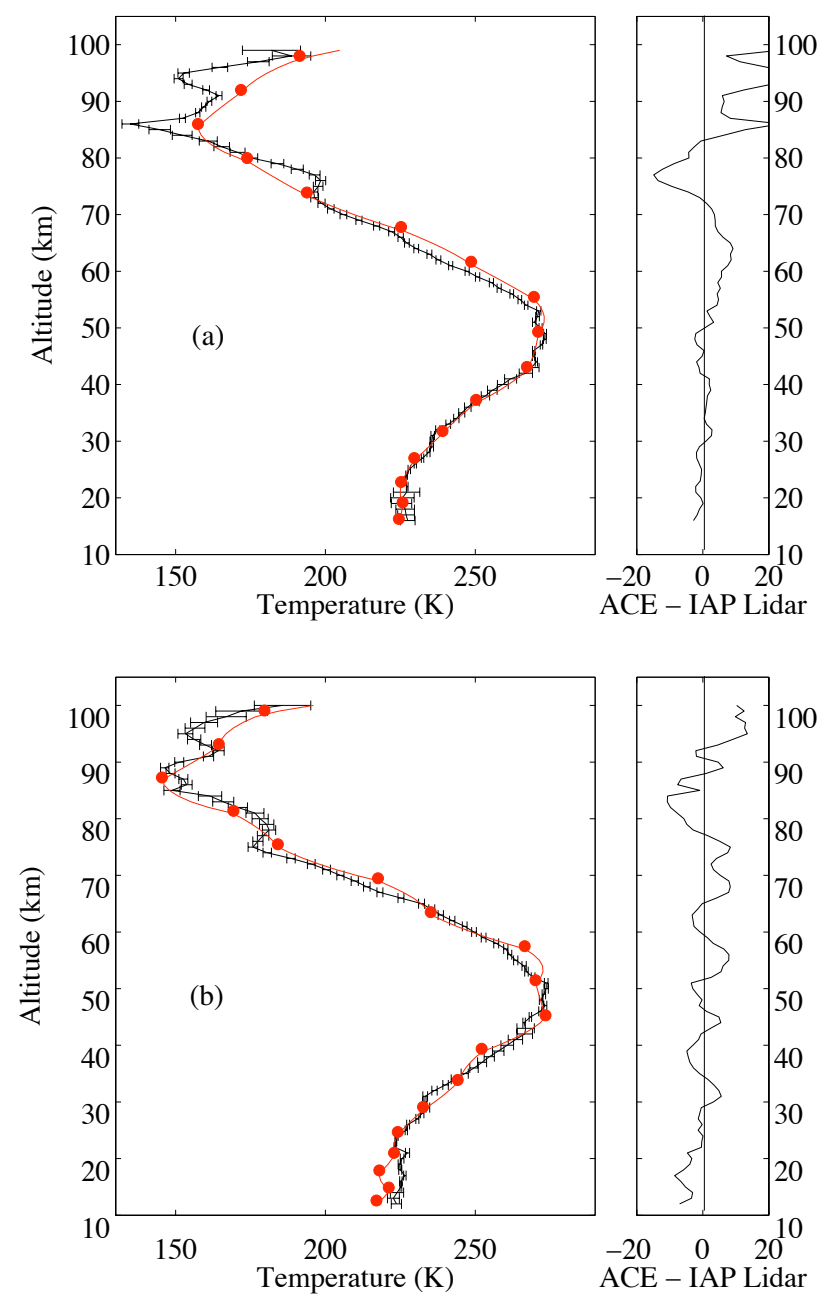

Fig. 8. Comparison of temperature profiles from Kühlungsborn lidar (black) and ACE-FTS v2.2 (red) on 21 July 2005 (a) and on 24 July 2006 (b). The top comparison shows larger differences (in $\mathrm{K}$ ) in the mesosphere, including an inversion layer measured by the lidar around $78 \mathrm{~km}$.

Raman Scattering measurements in the analysis yields an estimate of $\pm 1.7 \mathrm{~K}$ for the lower bound of the ACE-FTS random error.

\subsection{Kühlungsborn, Germany lidar}

Comparisons between the lidar temperature profiles from Kühlungsborn and ACE-FTS soundings were performed for all soundings that are within a distance of $500 \mathrm{~km}$ and a time of $2 \mathrm{~h}$. There were seven coincidences between February 2004 and December 2006. The typical time difference between the compared profiles is about $1.5 \mathrm{~h}$ as the lidar soundings are only performed during darkness and the ACEFTS observations during sunrise and sunset. The lidar temperature profiles were acquired over a $1 \mathrm{~h}$ integration time. 
Within the limits of the measurements there is a general agreement between the different instruments from the midstratosphere up to the stratopause and no obvious bias of one of the instruments. Some wavelike structures in the temperature difference profile between the two instruments (e.g. the lower plot in Fig. 8) appear to originate from the ACE-FTS data.

Above the stratopause, gravity and tidal waves become increasingly important, as is visible in the lidar measurements integrated for $60 \mathrm{~min}$. Within the ACE-FTS profiles, most of this variation is not captured as a consequence of the vertical sampling (about $6 \mathrm{~km}$ in this case) for these ACE-FTS occultations coincident with the lidar. Apart from what appears to be an example of previously-mentioned unphysical oscillations in the ACE-FTS profile (likely induced by an undersampled structure in the temperature profile), there is a good agreement between the ACE-FTS profile sr15870 on July 24 2006 (19:18 UT) and the lidar profile of 21:00-22:00 UT of the same day (Fig. 8). The spatial shift is only about $95 \mathrm{~km}$, i.e., the profile is one of the nearest ACE-FTS measurements to the lidar station. The remaining difference between lidar and the ACE-FTS v2.2 temperatures above $60 \mathrm{~km}$ can be attributed to the different vertical resolutions. Given the variability in mesospheric temperature structure observed with the lidar, one cannot expect excellent agreement in this region for measurements collected at different times and locations (Gerding et al., 2007b). However, accounting for this variability there appears to be a systematic high bias in the ACE-FTS temperatures above the stratopause. For most of the seven coincidences, ACE-FTS temperatures are about 1$10 \mathrm{~K}$ higher than the lidar values below $80 \mathrm{~km}$. Above $80 \mathrm{~km}$, the differences increase. While one might expect the differences in sampling to produce both positive and negative differences between the profiles, nearly all ACE-FTS profiles have higher temperatures than the lidar measurements.

\subsection{Poker Flat Research Range, Alaska lidar}

Comparisons between the lidar temperature profiles at Poker Flat Research Range and ACE-FTS measurements are performed for all ACE-FTS occultations within $100 \mathrm{~km}$ and $24 \mathrm{~h}$ of the lidar measurements. There are 10 such coincidences during six lidar observation periods between March 2004 and September 2005. The time difference between the compared profiles is as short as $1 \mathrm{~h}$ and as long as $24 \mathrm{~h}$, with a typical value of $7 \mathrm{~h}$ as the lidar soundings are only performed during darkness and the ACE-FTS observations during sunrise and sunset. The lidar observations are integrated between 3 and $14 \mathrm{~h}$, with an average of $9 \mathrm{~h}$.

There is no obvious systematic bias between the satellite and lidar measurements. The differences between the measurements have similar magnitude in both the stratosphere and the mesosphere. These differences are both positive and negative below $75 \mathrm{~km}$. There is a general positive bias in the lidar temperatures near $80 \mathrm{~km}$ that reflects a difference between the ACE-FTS measurements and MSISE-90 model, which is used to seed the lidar temperature retrieval and can influence the retrievals in the upper mesosphere.

Two coincident measurements are shown in Fig. 9. There is no systematic bias between the ACE-FTS profile on January 282005 (sr7881 at 14:08 UT) and the lidar profile obtained from 04:45-17:46 UT of the same day (top panel). The spatial difference between these measurements is less than $200 \mathrm{~km}$. Despite the difference in the vertical resolution of the measurements, both profiles show the same general features. Both the satellite and lidar measure a double maximum at the stratopause and a single maximum near $70 \mathrm{~km}$. The maximum near $70 \mathrm{~km}$ appears to be a mesospheric inversion layer with near adiabatic lapse rate between 70 and $75 \mathrm{~km}$. The ACE-FTS profile of 9 September 2005 at 16:12 UT (sr11181) and the lidar profile obtained between 06:08-09:15 UT of the same day show better agreement in the mesosphere than the stratosphere (Fig. 9 lower panel). The spatial difference for this coincidence is less than $500 \mathrm{~km}$. The ACE-FTS temperatures are up to $5 \mathrm{~K}$ colder in the stratosphere, while the lidar temperatures are up to $5 \mathrm{~K}$ colder in the mesosphere.

\subsection{SPIRALE flight from Kiruna, Sweden}

One SPIRALE flight was successfully completed near Kiruna (Sweden, $67.7^{\circ} \mathrm{N}, 21.6^{\circ} \mathrm{E}$ ) on 20 January 2006. A vertical profile of temperature was measured during the slow balloon ascent, between 17:50 and 19:50 UT. Pressure and temperature measurements were acquired every $1.1 \mathrm{~s}$, providing a vertical resolution of about 1 to $4 \mathrm{~m}$. However this resolution has been degraded to $1 \mathrm{~km}$ by averaging all SPIRALE results within each $1 \mathrm{~km}$ layer for comparison with ACE-FTS data. The best coincidence has been obtained for the ACE-FTS occultation sr13151, which occurred 12-13 h later (21 January 2006, 08:00 UT) at a distance of about $400 \mathrm{~km}\left(64.3^{\circ} \mathrm{N}, 21.6^{\circ} \mathrm{E}\right)$ from the SPIRALE balloon measurement. Therefore, prior to the intercomparison, the SPIRALE profile was corrected for this spatial and temporal mismatch. The correction was done according to Eq. (C15) of von Clarmann (2006) and using temperature profiles obtained by interpolating in space and time ECMWF fields with a spatial resolution of $0.5^{\circ} \times 0.5^{\circ}$ and a temporal resolution of $3 \mathrm{~h}$. The intercomparison of SPIRALE and ACE-FTS measurements is shown in Fig. 10. The altitude range selected for temperature comparisons is from 14 to $27.4 \mathrm{~km}$, where data are available for both instruments. The SPIRALE in situ profile does not show any vertical oscillation features, unlike the ACE-FTS profile, which gives a second temperature minimum around $23 \mathrm{~km}$ height similar to SABER. This feature is likely an artifact in the retrieval due to the empirical form of the pressure profile employed (Sect. 4). In a comparison with a preliminary version of the next generation ACE-FTS temperature retrievals (e.g. v3.0), the feature is no longer evident. The ACE-FTS temperatures are on average about $3.2 \mathrm{~K}$ 

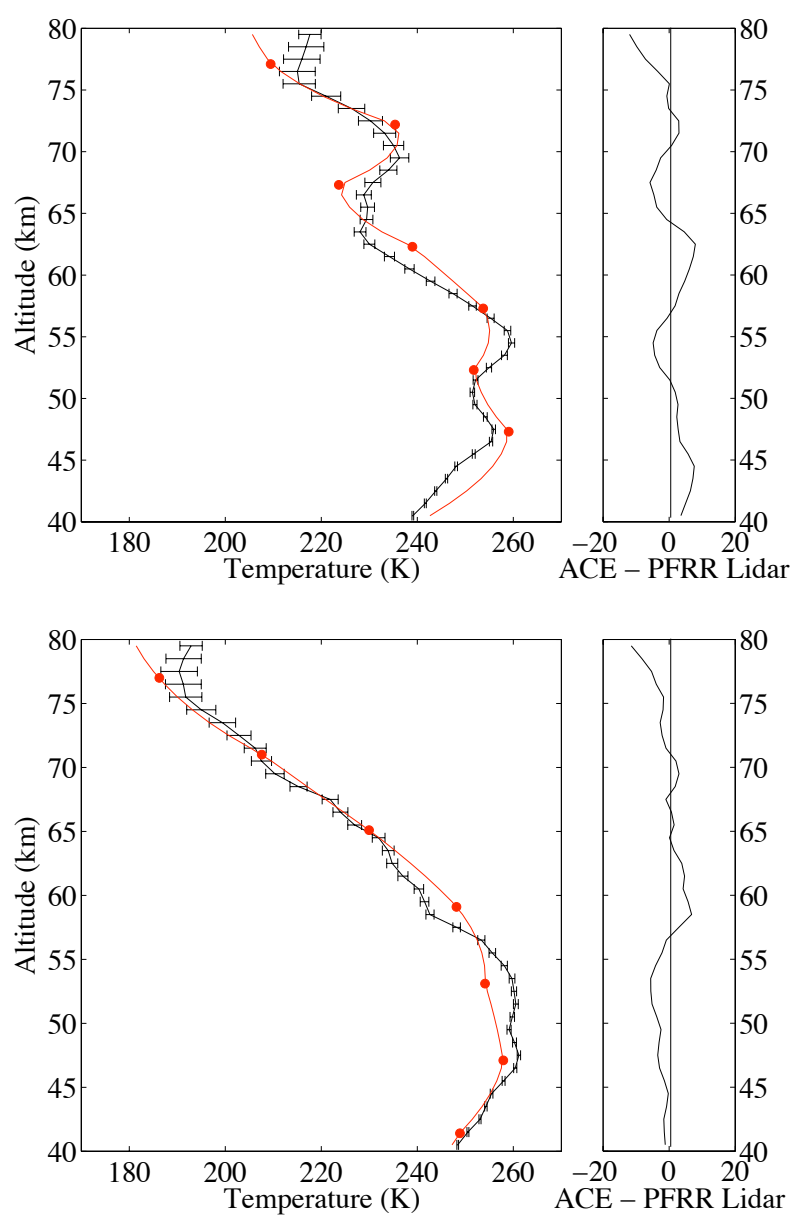

Fig. 9. Comparison of temperature profiles (in K) from Poker Flat Research Range (black) and ACE-FTS v2.2 (red) on 28 January 2005 (top) and on 9 September 2005 (bottom). The top comparison shows larger temperature differences than the lower comparison. However, the inversion layer around $70 \mathrm{~km}$ is evident in both measurements in the top comparison.

higher than the SPIRALE values over the altitude range 14$28 \mathrm{~km}$, with a standard deviation of $\pm 3.4 \mathrm{~K}$.

\subsection{Eureka, Canada lidar}

Rayleigh temperatures were calculated and compared to the ACE-FTS v2.2 temperature profiles for periods during three of the Canadian Arctic ACE Validation Campaigns (Kerzenmacher et al., 2005): 20 February-8 March 2004, 23 February-4 March 2005 and 21-26 February 2006. In most cases, the sunset ACE-FTS temperature profile was compared to the Rayleigh profile collected the following morning. In the interest of completeness, some ACE-FTS profiles were compared to both the preceding and following Rayleigh profiles. However, only those ACE-FTS occultations that were within $10 \mathrm{~h}$ of the lidar scan end time were used in the

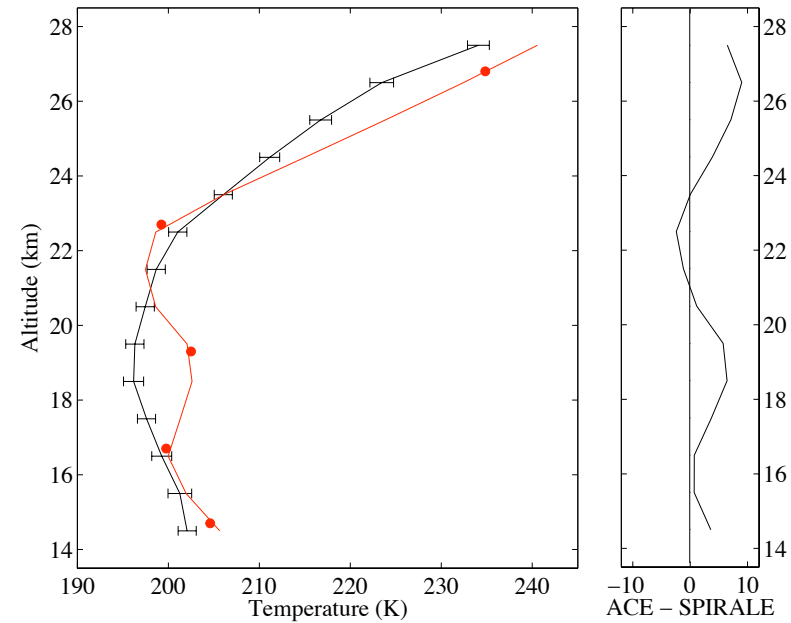

Fig. 10. Comparison of ACE-FTS v2.2 (red) temperature profile with SPIRALE balloon-borne (black) temperature measurements (in K) near Kiruna, Sweden on 20 January 2006. Description of plotting convention is given in Fig. 5 caption.

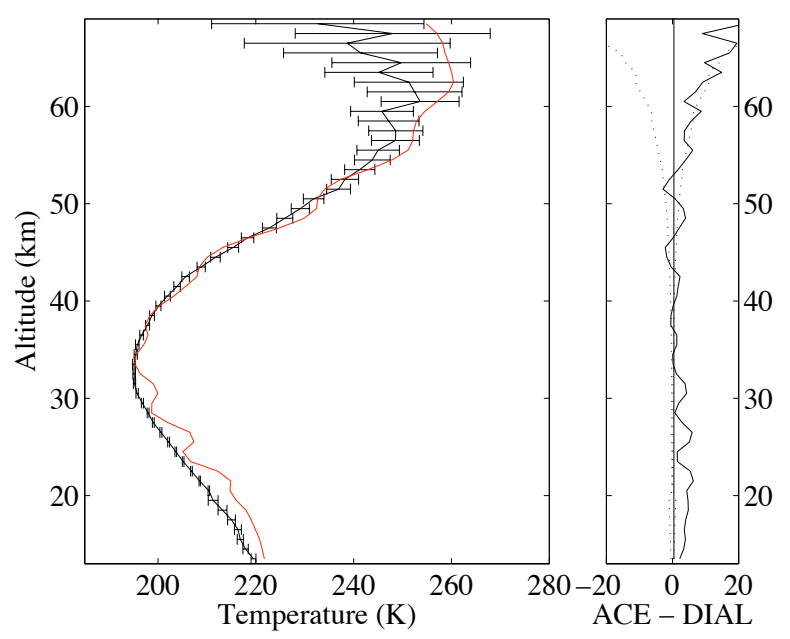

Fig. 11. Seasonal average temperature profiles and differences (in K) for the Eureka DIAL (black) and ACE-FTS v2.2 (red) using 16 nights of measurements during the 2004 and 2006 Canadian Arctic ACE Validation campaigns. The error bars are 1- $\sigma$ standard deviations of the mean, also shown as a dotted line in the right-hand panel (in K).

seasonal averages (a similar methodology to Kerzenmacher et al., 2005).

The ACE-FTS temperature profile was on average smoother than the Rayleigh temperature profile for all three years. This is expected, since the lidar data are binned at $300 \mathrm{~m}$ compared to $4 \mathrm{~km}$ for the ACE-FTS profile.

Seasonal averages were calculated for 2004, 2005 and 


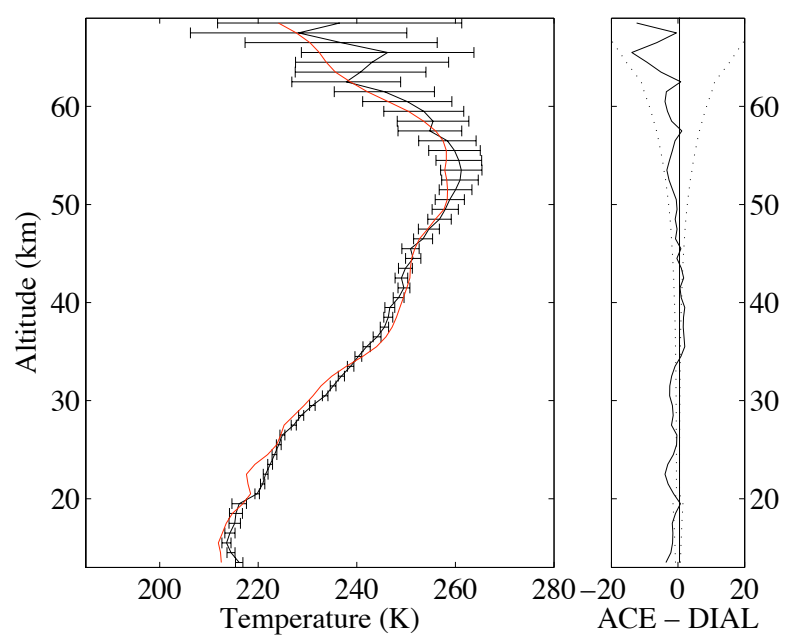

Fig. 12. Seasonal average temperature profiles and differences (in K) for the Eureka DIAL (black) and ACE-FTS v2.2 (red) using 5 nights of measurements during the 2005 Canadian Arctic ACE Validation campaign. The error bars are $1-\sigma$ standard deviations of the mean, also shown as a dotted line in the right-hand panel (in K).

2006 using those dates where the time difference between the two instruments was a minimum. Despite the daily disagreements between the two instrument's measurement of temperature, the three seasonal averages are consistent in terms of gross features and inter-seasonal differences. Manney et al. (2007) found 2004 and 2006 had similar temperature structures, but 2005 was significantly different. Figure 11 shows the seasonal average for 2004 (13 nights) and 2006 (3 nights) together, while Fig. 12 shows the average for 2005 (5 nights). Temperatures measured by both instruments show a marked difference in 2005. As discussed by Manney et al. (2007), during both the 2004 and 2006 campaigns, measurements at Eureka were inside the polar vortex, where upper stratospheric temperatures were unusually low and lower stratospheric temperatures unusually high in the aftermath of strong, prolonged stratospheric sudden warmings, resulting in an unusual temperature structure with a minimum near $30-40 \mathrm{~km}$ (consistent with the minima near $32-33 \mathrm{~km}$ and $37 \mathrm{~km}$ in 2004 and 2006, respectively, in the seasonal averages shown here). In contrast, the 2005 winter stratosphere was unusually cold throughout the stratosphere until an early final warming in late February (upper stratosphere) to lateMarch (lower stratosphere) during which the polar vortex moved away from Eureka. Thus, 2005 temperature profiles at Eureka had a much more typical structure, with tropopause and stratopause altitudes comparable to standard atmosphere values (Salby, 1996); the upper stratosphere was warmer than in the other years because the final warming had already begun and the vortex moved away from Eureka at those levels.

The temperatures obtained by both instruments differ on the smaller scale, with the ACE-FTS temperature profiles

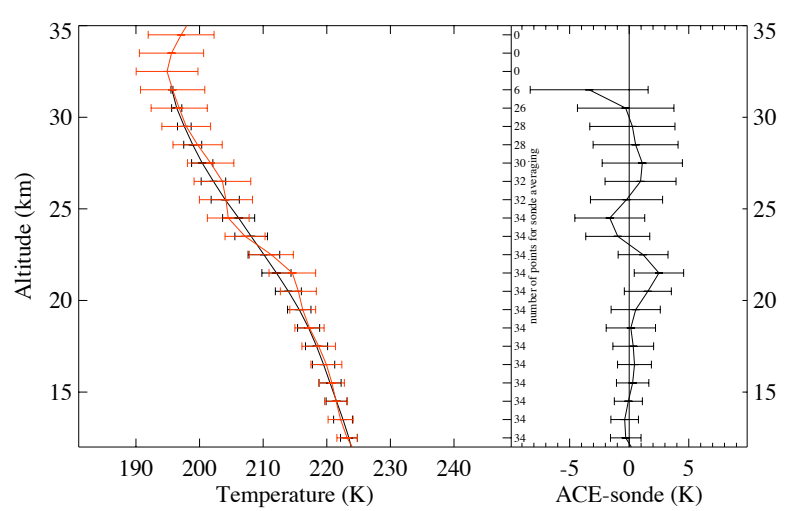

Fig. 13. Mean temperature profiles from ACE-FTS v2.2 (red) and radiosonde (black) during 2004 Canadian Arctic ACE Validation Campaign (left panel). The horizontal bars indicate the 1- $\sigma$ standard deviation of the mean of the respective measurements. The mean of the differences between the ACE-FTS v2.2 and the radiosonde temperature profiles is shown in the right panel with 1- $\sigma$ standard deviation shown as error bars. The number of profiles included in the mean calculation at each altitude is indicated vertically between the plots.

having a positive bias with respect to the Rayleigh temperature profiles in 2004 and 2006. In 2004, the bias reached a maximum of $+5 \mathrm{~K}$ near $20 \mathrm{~km}$, reduced to $+1 \mathrm{~K}$ above $40 \mathrm{~km}$ and increased beyond $+10 \mathrm{~K}$ near the stratopause at $60 \mathrm{~km}$. In 2005, the ACE-FTS bias was somewhat negative, especially above $50 \mathrm{~km}$. At lower altitudes, the two instruments measure temperatures which differed by as much as $5 \mathrm{~K}$ : $+4 \mathrm{~K}$ at $19 \mathrm{~km}$ and $-5 \mathrm{~K}$ at $31 \mathrm{~km}$. In 2006, the temperature differed by as much as $+8 \mathrm{~K}$ at $20 \mathrm{~km}$, reducing to $+3 \mathrm{~K}$ near $50 \mathrm{~km}$. The differences in 2005 and 2006 above $55 \mathrm{~km}$ are noisy due to the low number of measurements included in the averages and the large uncertainties in the lidar data at that altitude. Manney et al. (2007) showed that a low bias of the lidar profiles with respect to satellite data (including ACE-FTS) in 2004 and 2006, and a slight high bias in 2005, near the top of the lidar profiles was consistent with the magnitude and direction of temperature differences due to the initial seed value used for the lidar retrievals.

\subsection{Eureka, Canada radiosondes}

Coincident ACE-FTS and radiosonde measurements, made during the 2004, 2005, and 2006 Canadian Arctic ACE Campaigns (Kerzenmacher et al., 2005), were identified by taking all pairs within $500 \mathrm{~km}$ in distance and $12 \mathrm{~h}$ in time. Figures 13, 14 and 15 for 2004, 2005 and 2006 (respectively) show the mean temperatures for both the radiosondes and ACE-FTS. In this section, the comparisons are divided up by year. The location of the polar vortex was considered using the Derived Meteorological Products (DMPs) for the ACE- 


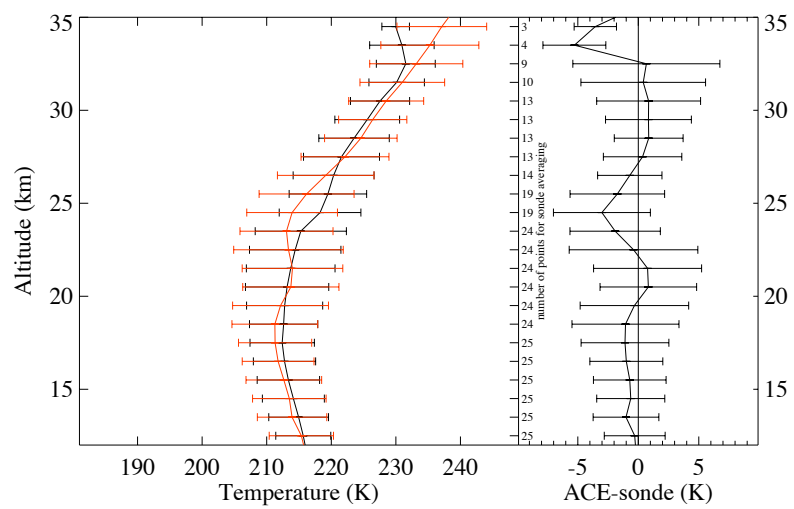

Fig. 14. Mean temperature profiles from ACE-FTS v2.2 (red) and radiosondes (black) during the 2005 Canadian Arctic ACE Validation Campaign (left) and the mean of the differences between the two data sets (right). Description of plotting convention is given in Fig. 13.

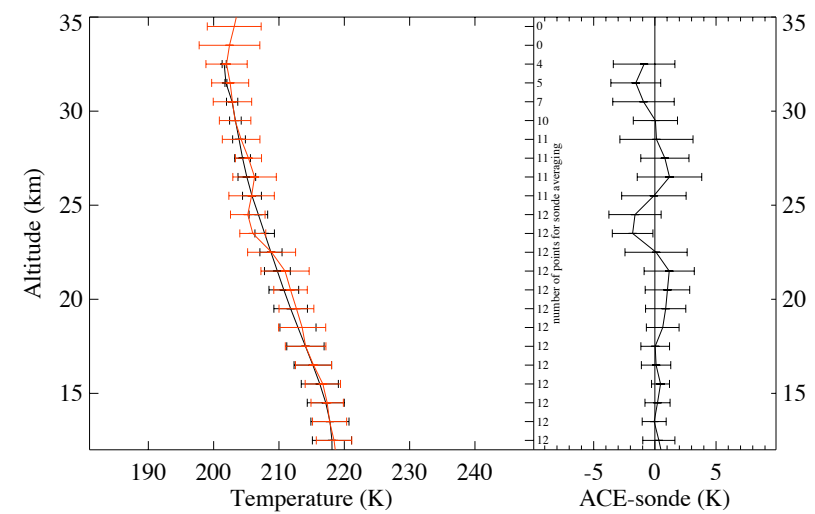

Fig. 15. Mean temperature profiles from ACE-FTS v2.2 (red) and radiosondes (black) during the 2006 Canadian Arctic ACE Validation Campaign (left) and the mean of the differences between the two data sets (right). Description of plotting convention is given in Fig. 13.

FTS occultation measurements and for radiosonde data from Eureka (Manney et al., 2007) but was found not to significantly change the results when computing the average. Using the comparisons in Figs. 13, 14 and 15, we find that the agreement between the ACE-FTS v2.2 temperature data and the radiosondes is within $\pm 3.4 \mathrm{~K}$ in $2004, \pm 3.0 \mathrm{~K}$ in 2005 , and $\pm 1.8 \mathrm{~K}$ in 2006 for the height range of $12-33 \mathrm{~km}$. ACEFTS appears to show a low bias with respect to radiosondes near $23 \mathrm{~km}$, similar to that seen in comparisons with SABER and SPIRALE.

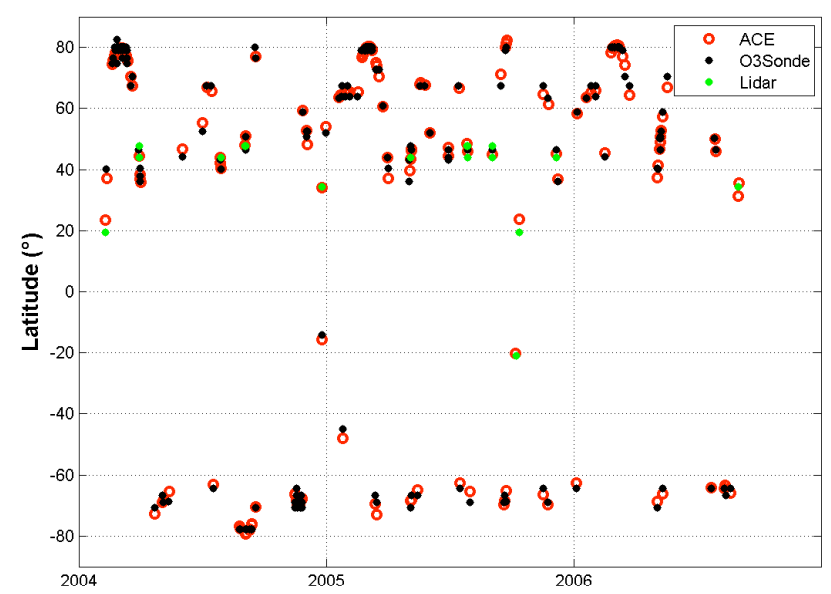

Fig. 16. Time latitude coverage of collocations between ACE-FTS and ground-based and in situ temperature measurements from the GAW and NDACC sites.

\subsection{Comparison with GAW and NDACC site radiosondes and lidars}

For comparison with the GAW and NDACC site radiosondes and lidars a collocation criteria of $500 \mathrm{~km}$ in space from the ground-based station to the ACE-FTS tangent point and $12 \mathrm{~h}$ in time were chosen as the best compromise between a sufficient number of comparison points and a sufficient collocation of the probed air masses. Reducing the spatial coincidence criteria decreases significantly the number of collocations available and limits the statistical relevance of the results. The time-latitude coverage of collocations between ACE-FTS and ground-based data are illustrated in Fig. 16. Collocations cover mostly the middle and high latitudes regions. Unfortunately, the number of collocated profiles found in the intertropical zone and in the Southern midlatitudes is too small to allow meaningful statistical comparisons. Therefore, our analysis concentrates on Northern middle latitudes and on the polar regions.

The comparisons were undertaken in three stages. First, each pair of collocated temperature profiles was plotted versus altitude and examined. The objective of this qualitative analysis was to identify global features and any possible issues in the temperature profiles. After this individual step, the variation of the measurements versus time was analysed. The time series of ACE-FTS profiles together with the time series of ground-based measurements were studied and a detailed analysis of their relative differences was performed. From this analysis, time periods with homogeneous results, from which statistical values may be deduced and are meaningful, were identified. Finally, the vertical structure of the differences was analysed within homogeneous time periods. Stations showing similar variations were grouped by latitude.

Differences were calculated as ACE-FTS minus 

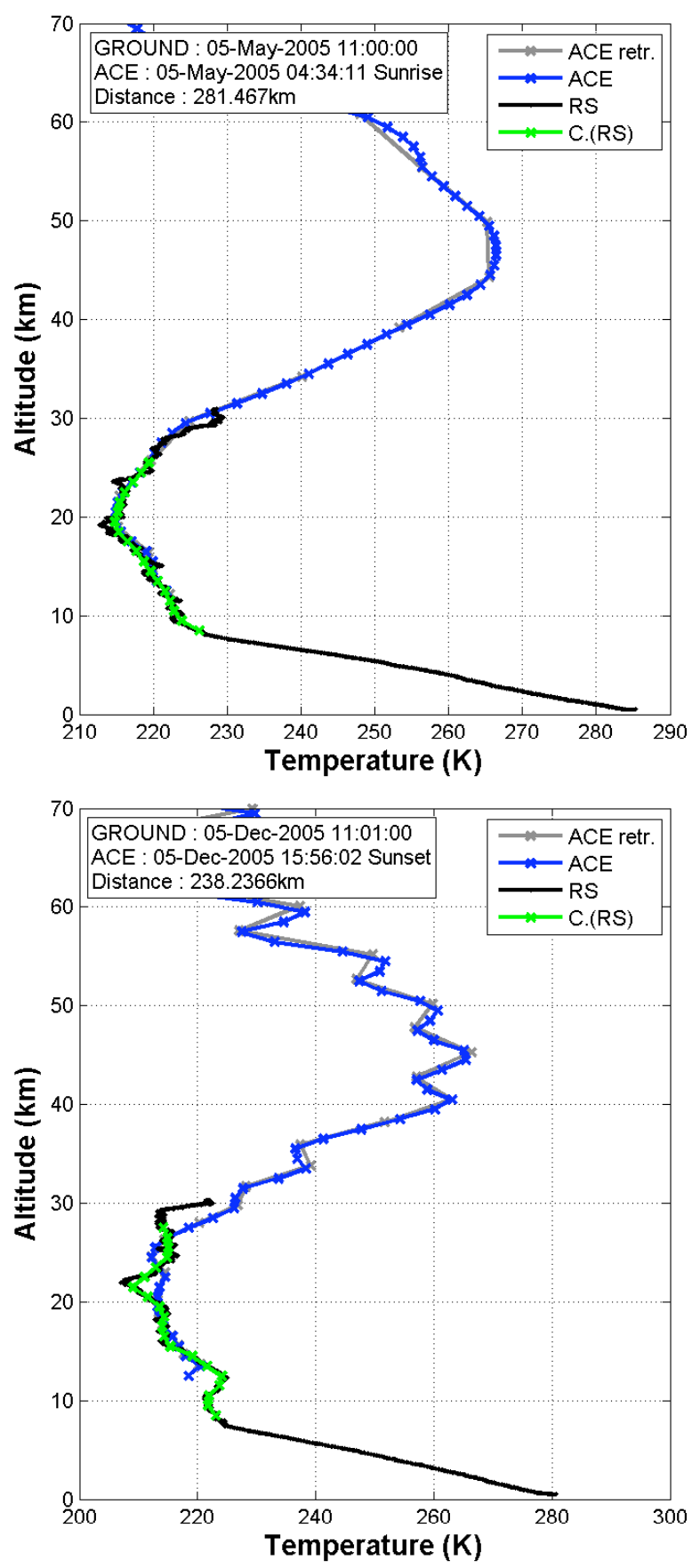

Fig. 17. Vertical temperature profile as retrieved from ACE-FTS measurement (grey) and interpolated on $1 \mathrm{~km}$ grid (blue) on 5 May 2005 (top panel) and on 5 December 2005 (bottom panel). Collocated temperature profile measured by radiosonde launched from Payerne Alpine station (black) and interpolated to ACE-FTS altitude grid is shown (green).

ground-based measurement. The high-resolution radiosonde and lidar profiles were first integrated within partial columns corresponding to ACE-FTS measurement

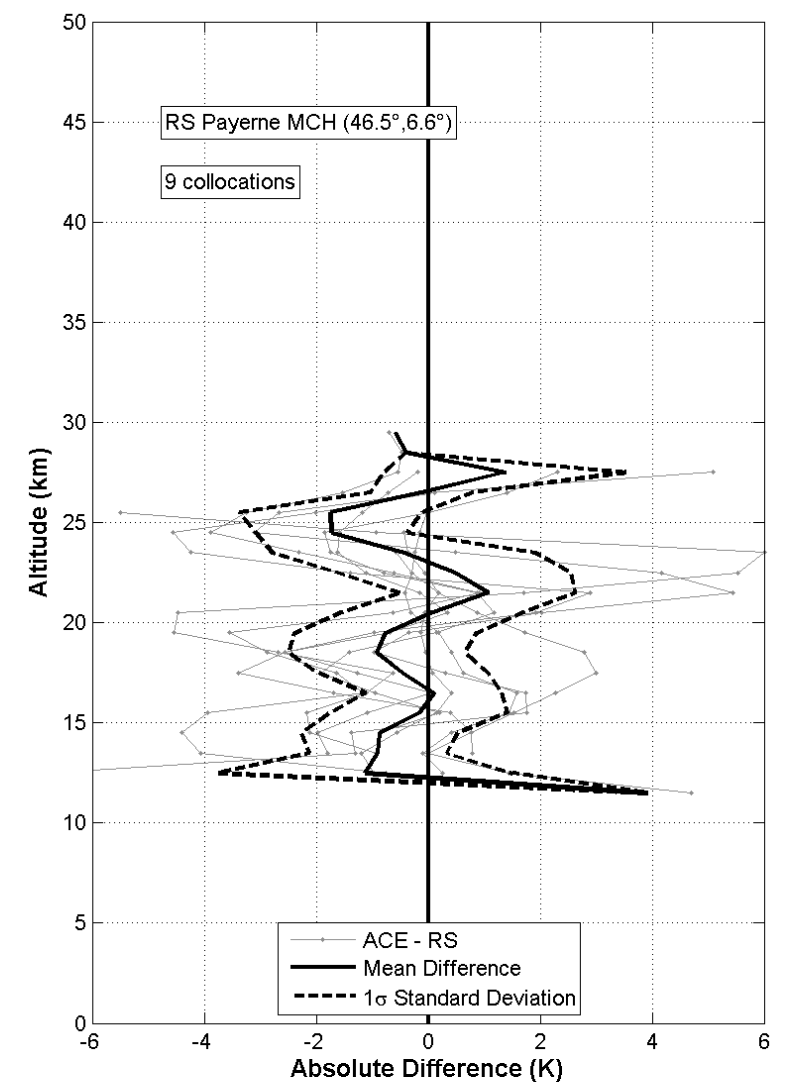

Fig. 18. Difference between each pair of ACE-FTS v2.2 and radiosonde temperature profiles at the Alpine station Payerne plotted versus altitude (grey lines). Corresponding mean (plain black line) and 1- $\sigma$ standard deviation (dashed black line) are also shown.

grid and then interpolated on the $1 \mathrm{~km}$ grid. Because no averaging kernels are available for the ACE-FTS retrievals, this operation was used to reduce the effect of vertical smoothing differences.

Figure 17 shows two examples of individual comparisons between retrieved ACE-FTS v2.2 temperature profiles and coincident radiosonde profiles at the Alpine station of Payerne in May and December 2005. The ACE-FTS v2.2 profiles for both coincidences show the expected shape. However, unphysical oscillations in the stratosphere and mesosphere are observed in the December 2005 profile. Excluding the oscillating structure, the ACE-FTS temperature profile is close to the correlative radiosonde profile in their common altitude range.

Next, a time series analysis was performed and, within the stratosphere, no important structure or seasonal variation was identified in the comparison results for ACE-FTS v2.2 and the radiosondes and lidars. This result may be due to a sparse seasonal sampling of the ACE-FTS occultation measurements. Consequently, we can derive meaningful statistics for ACE-FTS vertical temperature profile agreement 


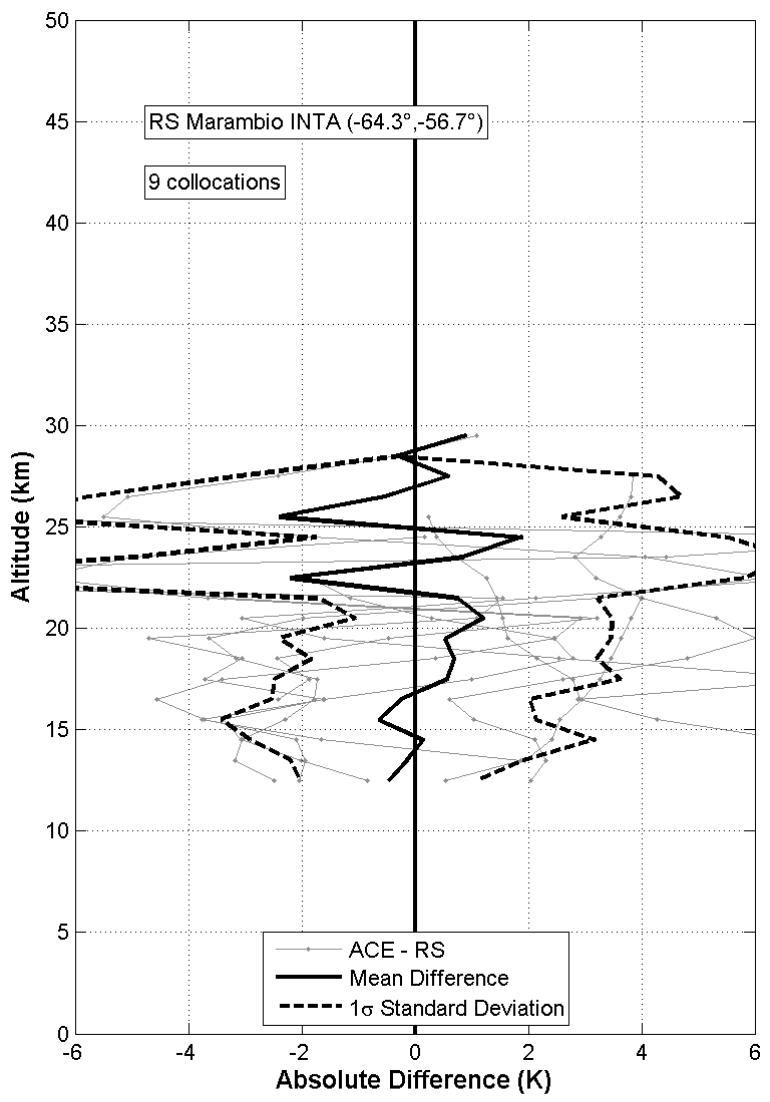

Fig. 19. Same as Fig. 18 but at the Antarctic station Marambio.

with correlative measurements over the three years, 20042006. Drawing data from throughout the complete time period helps also to gather a statistically relevant number of coincidences at each station.

Figure 18 shows vertical statistics for the 2004-2006 time period of the differences between ACE-FTS v2.2 temperature profiles and the radiosonde profiles measured at the Alpine station Payerne. The mean difference varies with altitude within $\pm 2 \mathrm{~K}$ from 10 to $30 \mathrm{~km}$. The unphysical oscillations in the ACE-FTS temperature profile affect the comparisons and result in oscillations in the differences. Amplitude of the oscillating pattern is larger above $20 \mathrm{~km}$, while in the lower part of the profile a better agreement, within $\pm 1 \mathrm{~K}$, is found. The 1- $\sigma$ standard deviation of the results is about $\pm 1.5 \mathrm{~K}$. Figure 19 shows an example of the results obtained at the Antarctic station of Marambio. Although the mean standard deviation still fits within the $\pm 2 \mathrm{~K}$ level, the result bears a larger standard deviation in the upper part of the comparison altitude range with a variability of $\pm 4 \mathrm{~K}$ above $20 \mathrm{~km}$ with the unphysical oscillations still present.

Figure 20 show statistics of comparisons between ACEFTS and lidar profiles measured at the European groundbased station Haute Provence. The mean difference is around

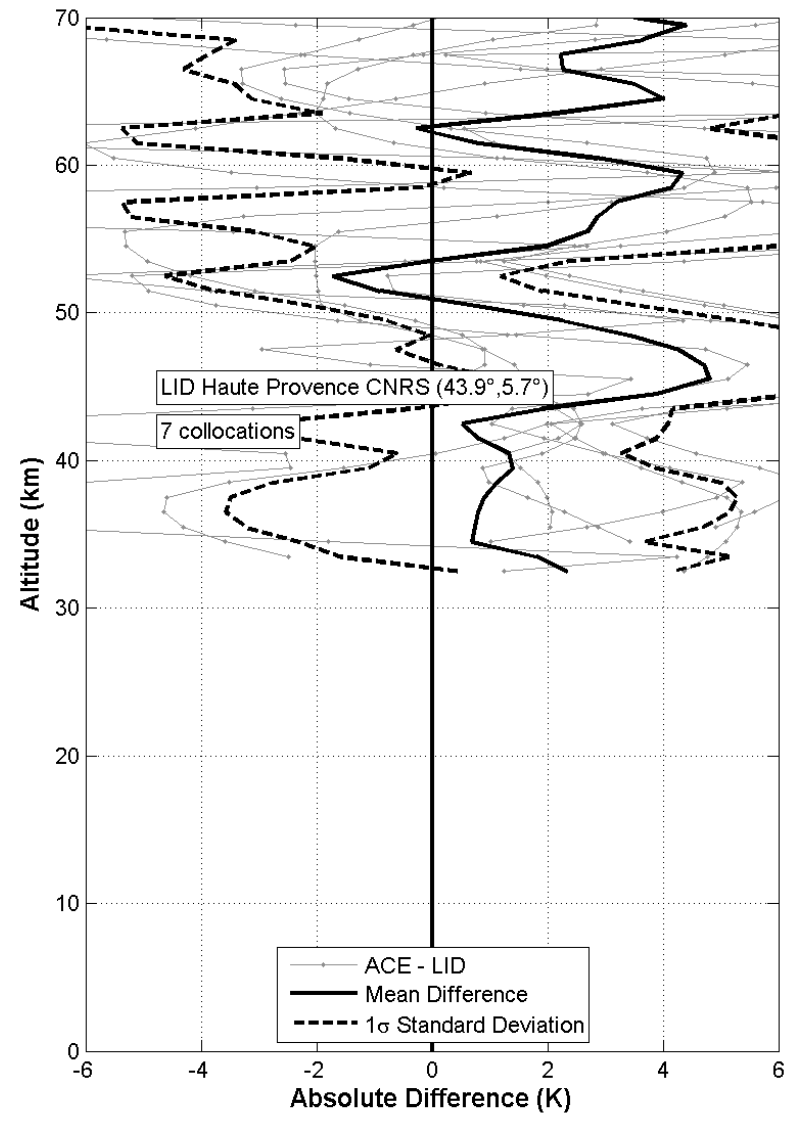

Fig. 20. Same as Fig. 18 but for comparison with lidar data at the European station Haute Provence.

$2 \mathrm{~K}$ and shows again the unphysical oscillating structure of $\pm 2 \mathrm{~K}$ of amplitude. The amplitude is greater at higher altitude and consequently has a larger impact on comparisons with lidar than with radiosondes. Apart from the oscillating pattern, the mean difference observed seems to indicate a positive bias of about $2 \mathrm{~K}$, which may be caused by atmospheric tides since the lidar measurements are taken at night while the ACE measurements are at sunrise and sunset. The systematic time difference between the measurements may result in systematic differences between the temperature profiles, in particular at $50 \mathrm{~km}$ altitude where the atmospheric tidal amplitude is maximum. Such discrepancies have already been mentioned in other studies and are a known limitation to the satellite temperature validation with lidar data (Keckhut et al., 2004, 1996).

At other ground-based stations, we obtain similar results. In general, a mean agreement within $\pm 2 \mathrm{~K}$ is observed with radiosondes from $10 \mathrm{~km}$ up to the burst point around $30 \mathrm{~km}$. Comparisons with lidar data give a poorer agreement and are more affected by the oscillations detected in the ACE-FTS profiles. The standard deviation is about $\pm 2 \mathrm{~K}$. The validation results versus radiosondes are summarised in Fig. 21. 

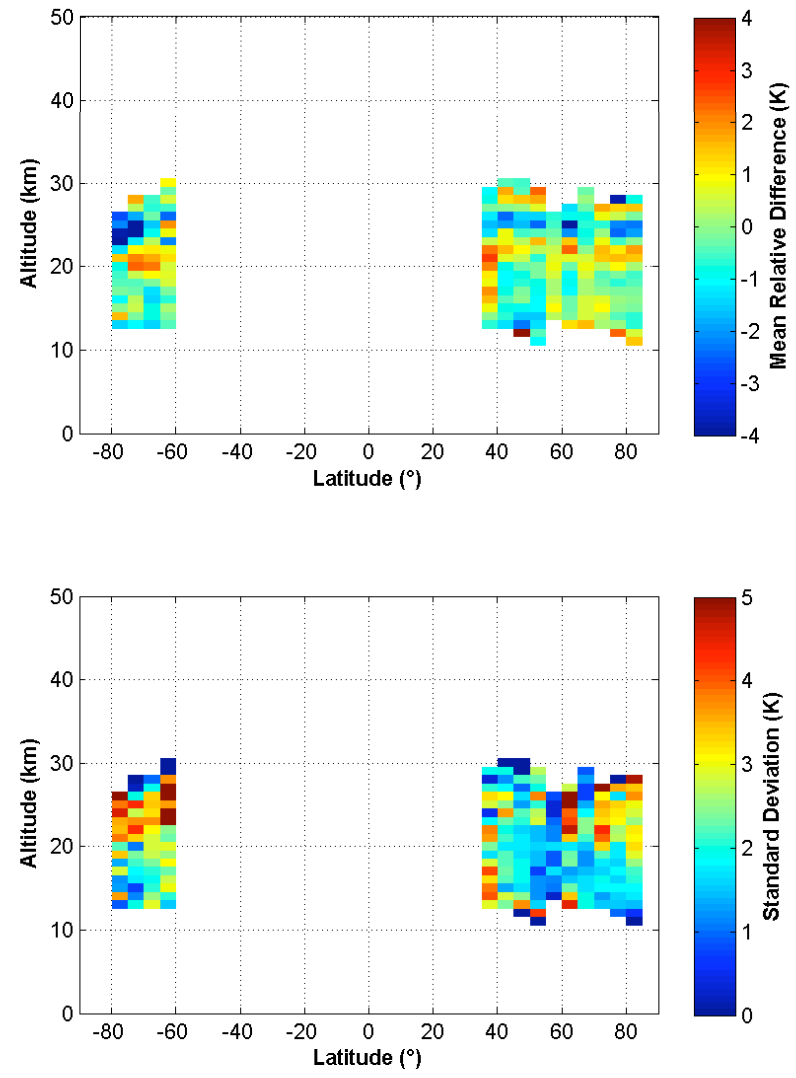

Fig. 21. Differences between ACE-FTS and radiosonde data versus altitude and latitude (top) and corresponding standard deviation (bottom) averaged in $5^{\circ}$ latitude bins.

This figure shows mean differences and corresponding standard deviations versus altitude and latitude for the 20042006 period. From $10 \mathrm{~km}$ up to $20 \mathrm{~km}$ the observed mean difference between ACE-FTS and radiosonde data are small $( \pm 2 \mathrm{~K})$. Such deviations may be accounted for in the systematic error budget of the comparison considering a reasonable contribution from ACE-FTS. Above $20 \mathrm{~km}$, although the mean difference is within the $\pm 2 \mathrm{~K}$ level, the detected unphysical oscillating pattern in the ACE-FTS temperature profile begins to affect the comparison, resulting in alternating $5 \mathrm{~km}$ wide bands of positive and negative differences. Also, ACE-FTS appears to be $2 \mathrm{~K}$ cooler around $23 \mathrm{~km}$ altitude, as has been previously noted for SABER, SPIRALE and the Eureka radiosonde measurements.

\section{ACE-FTS preliminary version 3.0}

As described previously, some occultations suffer from unphysical oscillations in the ACE-FTS version 2.2 temperature profiles. The next generation of the ACE-FTS software (to be called version 3.0) is currently under development, but changes have been incorporated in the temperature retrieval to fix this problem.
An oscillatory solution in a least squares analysis is often a symptom of poor constraints. ACE-FTS retrievals employ no explicit smoothing and are therefore susceptible to unphysical oscillations in retrieved profiles under adverse conditions. Unphysical oscillations were previously observed in ACE-FTS version 2.1 volume mixing ratio (VMR) retrievals, particularly in altitude regions where the signal was close to the noise (Boone et al., 2005). It was these unphysical oscillations that precipitated the change to version 2.2. To fix the problem, a change was made in the interpolation approach from the measurement grid to the $1-\mathrm{km}$ grid. The new interpolation approach introduced off-diagonal elements in the Jacobian matrix for the least squares analysis that imposed an effective regularization on the solution, yielding smoother VMR profiles.

The ACE-FTS temperature retrievals are generally less susceptible to unphysical oscillations than the VMR retrievals, thanks in part to the large number of microwindows used in pressure/temperature retrievals. Plus, unlike the VMR retrievals, there are no altitude regions in the pressure/temperature retrievals where all of the spectral features used in the analysis are close to the noise limit. Hence, no change was made between versions 2.1 and 2.2 for the interpolation of temperature from the measurement grid to the 1-km grid. The implicit smoothing induced by the change of interpolation approach was not deemed necessary. However, a study of the ACE-FTS version 2.2 temperature results revealed two situations that could lead to unphysical oscillations in the temperature retrievals.

There is often structure in mesospheric temperature profiles, a consequence of processes such as gravity waves, planetary waves, and tides. The amplitude of this structure can be relatively large, on the order of $10 \mathrm{~K}$ or larger. When the amplitude of the temperature structure in the mesosphere is relatively large and the ACE-FTS cannot fully resolve the structure, unphysical oscillations can (but not always will) occur in the retrieval results. This effect can be exacerbated when the altitude sampling of ACE-FTS measurements is high (around $2 \mathrm{~km}$ ). Figure 22 shows these unphysical oscillations for a single occultation measurement (top panel). The lower panel of the figure shows that the oscillations will not necessarily be averaged out when the derived temperatures are averaged. The unphysical oscillations in the retrievals are reliably suppressed by changing the interpolation approach used to cast temperatures from the measurement grid onto the 1-km grid, similar to what was done for VMRs in version 2.2. This new interpolation approach has been implemented in the next generation of the processing software. Unfortunately, real structure with an altitude extent comparable to the measurement spacing will also be at least partially suppressed with the new interpolation approach, but that cannot be avoided. Figure 22 (the red curves labeled "v3.0") shows examples of the new interpolation approach compared to version 2.2 retrievals. 

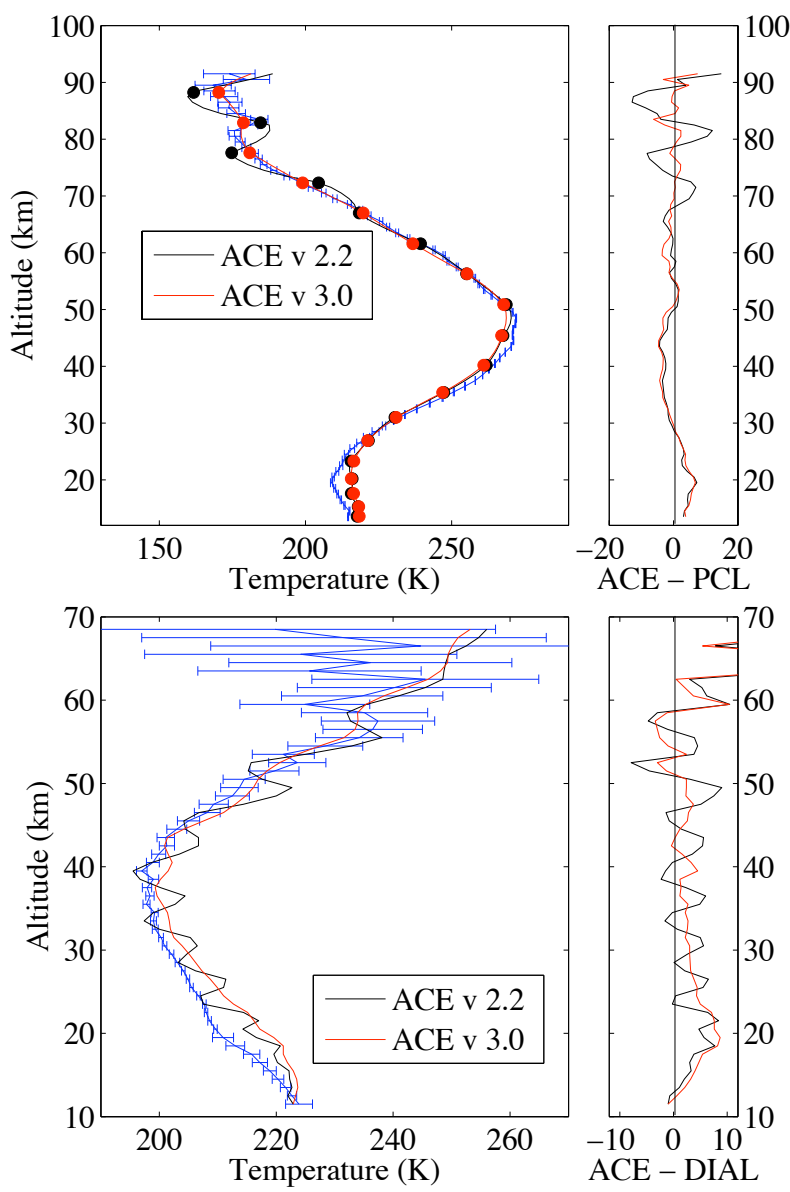

Fig. 22. Examples of unphysical oscillations in an individual ACEFTS comparison with the Purple Crow Lidar (top) and with an average of 3 ACE-FTS profiles on 3 nights in 2006 compared to the Eureka Lidar (bottom). Note that oscillations may persist in average profiles, particularly for small numbers of profiles averaged in similar measurement conditions. The measurements in the top panel are the same as in Fig. 7, with the ACE-FTS version 2.2 temperature retrievals in black. The ACE-FTS preliminary version 3.0 temperatures (red) show the damping of the unphysical oscillations seen in the version 2.2 temperature retrievals.

Unphysical oscillations in version 2.2 temperature results can also occur in the stratosphere when there is a temperature minimum above about $30 \mathrm{~km}$, a situation most commonly found in the polar region during spring. Recall that instrument pointing information (i.e., the tangent heights associated with the measurements) are derived from the analysis below $43 \mathrm{~km}$. For some occultations, the analysis yields oscillations in the temperature profile accompanied by compensating oscillations in the derived tangent heights. The new interpolation approach reduces the number of these occurences but does not eliminate them. The first measurement below $43 \mathrm{~km}$ is only displaced slightly (as a result of refrac- tion effects) from the expectations of geometry, at most 10 $50 \mathrm{~m}$. A relaxed constraint is applied in the software that the tangent height of the first measurement below $43 \mathrm{~km}$ is known to within $100 \mathrm{~m}$, a constraint that greatly improves the behavior of the retrievals for this variety of occultation.

As described in Boone et al. (2005), pressure at low altitude is expressed as an empirical function of the ratio of the baseline in two locations within the $\mathrm{N}_{2}$ continuum. The systematic cold bias of $\sim 2 \mathrm{~K}$ or "bump" near $23 \mathrm{~km}$ appears to have resulted from pushing the use of this empirical function too high in altitude. Examples of this feature can be seen in Figs. 2, 3, 10, 12 and 21. Version 3.0 of the ACE-FTS processing software will limit the use of the empirical function to slightly lower altitudes, improving the retrieval results near $23 \mathrm{~km}$.

In ACE-FTS version 2.2 retrievals, $\mathrm{CO}_{2}$ VMR is retrieved above about $70 \mathrm{~km}$ using an empirical function with five parameters (Boone et al., 2005). No constraint was imposed on the empirical function. Analysis of version 2.2 retrievals indicated that there was often a small (1-3\%) discontinuity in $\mathrm{CO}_{2} \mathrm{VMR}$ between the fixed profile at low altitude (below $70 \mathrm{~km}$ ) and the retrieved profile at high altitude, which leads to increased errors in temperature above $70 \mathrm{~km}$. A constraint has been added to the empirical function in the next generation processing software that does not permit a significant discontinuity near $70 \mathrm{~km}$.

\section{Conclusions}

ACE-FTS temperature profiles have been compared to correlative observations provided by satellites, balloons, radiosondes and lidar measurements. From $10 \mathrm{~km}$ up to around the stratopause, the mean difference is within $\pm 2 \mathrm{~K}$. The observed standard deviation ranges may be explained by contributions from atmospheric variability. In the mesosphere and lower thermosphere, the temperature differences are about a factor of 2 larger. Furthermore, the limitation of ACEFTS's vertical resolution can cause inversion layers and others small-scale structures to be smoothed out.

Some ACE-FTS version 2.2 temperature profiles suffer from unphysical oscillations. For scientific studies with ACE-FTS temperatures, caution is advised using a single profile. Studies that use averages may reduce the impact of unphysical oscillations, but oscillations may persist in the averages, particularly for a small number of profiles with similar measurement conditions (e.g. Fig. 22). The oscillations typically occur in the mesosphere, but can also occur in the stratosphere when there is a temperature minimum above about $30 \mathrm{~km}$. The effect of the temperature oscillations on VMR retrievals (which use ACE-FTS version 2.2 pressure/temperature retrievals as inputs) is minimized by compensating errors in other parameters. Oscillations in the retrieved temperatures are always accompanied by compensating oscillations in the retrieved tangent heights and/or 
pressures such that one obtains the appropriate density profile. As long as the microwindows used are relatively insensitive to temperature, VMR retrievals typically suffer changes of no more than a percent or so from oscillations in the temperature profile. Preliminary results from the next processing version of the ACE-FTS software do not suffer from these unphysical oscillations.

There is evidence for a high bias in the ACE-FTS temperatures in the mesosphere. In the lower mesosphere (roughly $50-70 \mathrm{~km}$ ), the discrepancy appears to be about $1-3 \mathrm{~K}$, particularly judging from the comparisons with the SABER and MIPAS data sets, where there are a relatively large number of coincidences (see Figs. 2 and 3). A slightly larger bias, e.g. 5-7 K, was reported by Schwartz et al. (2007) comparing ACE-FTS to MLS measurements. There is a possibility that the bias arises from the ACE-FTS pressure/temperature retrieval process itself, because there is a fundamental difference in the retrieval approach above and below $\sim 50 \mathrm{~km}$. However, this level of disagreement could simply be a consequence of differences in spectroscopic parameters used in the various analyses. The ACE-FTS analysis, for example, uses a set of microwindows from one spectral band that have an upper altitude limit of $46 \mathrm{~km}$, as well as a set of microwindows from a different spectral band with a lower altitude limit of $50 \mathrm{~km}$. Discrepancies in the spectroscopic constants for one of these bands could account for observed temperature errors on the order of $1 \%$. Preliminary tests with the next generation of the ACE-FTS processing software exhibit a smaller ACE-FTS bias in this region, but the bias does not disappear entirely. This issue remains under investigation.

The high bias of ACE-FTS temperatures found above $\sim 70 \mathrm{~km}$ in the comparisons with HALOE (for occultations without PMCs) and lidars is greater than that found in other satellite-ground-based comparisons. This high bias could be a consequence of the discontinuity often observed in $\mathrm{CO}_{2}$ VMR between the regions where the VMR is fixed (below $\sim 70 \mathrm{~km}$ ) and where it is retrieved (above $\sim 70 \mathrm{~km}$ ). In preliminary tests with the next generation processing software, the bias observed with the Purple Crow Lidar disappears, while the bias with HALOE is greatly reduced but does not disappear entirely, possibly a consequence of the small number of coincidences without PMC contamination (insufficient numbers to average out the mesospheric temperature variability for the given set of coincidences).

ACE-FTS temperatures in the upper mesosphere and lower thermosphere can be significantly different from ground-based sensors. This difference could be partly due to the altitude resolution of the ACE-FTS instrument, which is often too low to capture structure such as mesospheric inversion layers. Some of the difference is also probably geophysical in nature, a result of the separation in time and space between measurements being compared, as temperature in this altitude region is highly variable.

Judging from comparisons with the SABER, SPIRALE and radiosonde measurements, there is evidence of a small cold bias (about $2 \mathrm{~K}$ ) near $23 \mathrm{~km}$. In preliminary comparisons with the next generation of ACE-FTS processing this bias is reduced.

The agreement with ACE-FTS temperatures to other sensors is typically better than $2 \mathrm{~K}$ in the upper troposphere and stratosphere and $5 \mathrm{~K}$ in the lower mesosphere. Comparisons with the Purple Crow Lidar suggest that the random error in ACE-FTS temperature measurements has a lower limit of about $\pm 2 \mathrm{~K}$.

In general, the agreement with ACE-FTS and groundbased lidars in the stratosphere (and SPIRALE) and lower mesosphere is excellent. Like the other comparisons, there are some problems in the mesosphere above $70 \mathrm{~km}$. These problems are both in the ACE-FTS analysis used for v2.2 (e.g. the unphysical oscillations) and geophysical, particularly the appearance of mesospheric inversions, which often could not be resolved by ACE-FTS. The exception to this agreement were the comparisons with the Davis lidar. Despite relatively tight coincidence criteria the position of the polar vortex caused large spatial temperature gradients, which often resulted in poor agreement between the instruments compared to the other sites.

Acknowledgements. The Atmospheric Chemistry Experiment (ACE), also known as SCISAT, is a Canadian-led mission mainly supported by the Canadian Space Agency (CSA) and the Natural Sciences and Engineering Research Council of Canada (NSERC). The Canadian Arctic ACE Validation Campaign project has been supported by CSA, Environment Canada (EC), NSERC, the Northern Scientific Training Program and the Centre for Global Change Science at the University of Toronto. Logistical and on-site technical support for the 2006 ACE Arctic campaign was provided by the Canadian Network for the Detection of Atmospheric Change (CANDAC). CANDAC and PEARL are funded by the Canadian Foundation for Climate and Atmospheric Sciences, NSERC, the Canadian Foundation for Innovation, the Ontario Innovation Trust, the Ontario Ministry of Research and Innovation, and the Nova Scotia Research and Innovation Trust.

The Purple Crow Lidar is primarily supported by the Nature Sciences and Engineering Research Council (NSERC).

The Davis $\mathrm{OH}$ and Lidar observations are supported by the Australian Science Advisory Committee (ASAC) project numbers 701 and 737 .

Work at the Jet Propulsion Laboratory, California Institute of Technology, was done under contract with the National Aeronautics and Space Administration.

The correlative data from balloon-based ozonesonde and groundbased lidar used in this publication were obtained as part of WMO's Global Atmospheric Watch (GAW), including the contributing Network for the Detection of Atmospheric Composition Change (NDACC). They are publicly available via the NDACC data archive and the World Ozone and Ultraviolet Data Center (WOUDC) (see http://www.ndacc.organdhttp://www.woudc.org). We thank warmly several members of the NDACC community for fruitful discussions. The reported work was supported partly by the ProDEx projects ACE, CINAMON and Envisat Database. These projects rely on the sustained operation of lidar and ozonesonde stations, which are 
nationally funded and supported. We are grateful to the responsible institutes and thank their co-workers for generating and making available high quality observations.

The authors thank the SABER and HALOE Science and Data Processing Teams for providing the SABER and HALOE temperatures used in this work and for helpful discussions and comments on the manuscript. We also thank the MIPAS instrument and algorithm development teams for their contributions to this work, in addition to the Reviewers and Editor for their thoughtful comments.

Edited by: A. Richter

\section{References}

Alpers, M., Eixmann, R., Fricke-Begemann, C., Gerding, M., and Höffner, J.: Temperature lidar measurements from 1 to $105 \mathrm{~km}$ altitude using resonance, Rayleigh, and Rotational Raman scattering, Atmos. Chem. Phys., 4, 793-800, 2004,

http://www.atmos-chem-phys.net/4/793/2004/.

Antikainen, V., Paukkunen, A., and Jauhiainen, H.: Measurement accuracy and repeatability of Vaisala RS90 Radiosonde, Tech. rep., Vaisala Inc., 2002.

Argall, P., Sica, R., Bryant, C., Algara-Siller, M., and Schijns, H.: Calibration of the Purple Crow Lidar Vibrational Raman water vapour mixing ratio and temperature measurements, Can. J. Phys., 85, 119-129, doi:10.1139/P06-091, 2007.

Barath, F. T., Chavez, M. C., Cofield, R. E., Flower, D. A., Frerking, M. A., Gram, M. B., Harris, W. M., Holden, J. R., Jarnot, R. F., Kloezeman, W. G., Klose, G. J., Lau, G. K., Loo, M. S., Maddison, B. J., Mattauch, R. J., McKinney, R., Peckham, G. E., Pickett, H. M., Siebes, G., Solits, F. S., Suttie, R. A., Tarsala, J. A., Waters, J. W., and Wilson, W. J.: The Upper-Atmosphere Research Satellite Microwave Limb Sounder instrument, J. Geophys. Res., 98, 10751-17 062, 1993.

Baron, P., Merino, F., and Murtagh, D.: Simultaneous retrievals of temperature and volume mixing ratio constituents from nonoxygen Odin submillimeter radiometer bands, Appl. Optics, 40, 6102-6110, 2001.

Bernath, P. F., McElroy, C. T., Abrams, M. C., Boone, C. D., Butler, M., Camy-Peyret, C., Carleer, M., Clerbaux, C., Coheur, P. F., Colin, R., DeCola, P., Maziere, M. D., Drummond, J. R., Dufour, D., Evans, W. F. J., Fast, H., Fussen, D., Gilbert, K., Jennings, D. E., Llewellyn, E. J., Lowe, R. P., Mahieu, E., McConnell, J. C., McHugh, M., McLeod, S. D., Michaud, R., Midwinter, C., Nassar, R., Nichitiu, F., Nowlan, C., Rinsland, C. P., Rochon, Y. J., Rowlands, N., Semeniuk, K., Simon, P., Skelton, R., Sloan, J. J., Soucy, M.-A., Strong, K., Tremblay, P., Turnbull, D., Walker, K. A., Walkty, I., Wardle, D. A., Wehrle, V., Zander, R., and Zou, J.: Atmospheric Chemistry Experiment (ACE): Mission overview, Geophys. Res. Lett., 32, L15S01, doi:10.1029/2005GL022386, 2005.

Boone, C. D., Nassar, R., Walker, K. A., Rochon, Y., McLeod, S. D., Rinsland, C. P., and Bernath, P. F.: Retrievals for the atmospheric chemistry experiment Fourier-transform spectrometer, Appl. Optics, 44, 7218-7231, 2005.

Burns, G. B., French, W. J. R., Greet, P. A., Phillips, F. A., Williams, P. F. B., Finlayson, K., and Klich, G.: Seasonal variations and inter-year trends in 7 years of hydroxyl airglow rotational tem- peratures at Davis station $\left(69^{\circ} \mathrm{S}, 78^{\circ} \mathrm{E}\right)$, Antarctica, J. Atmos. Terr. Phys., 64, 1167-1174, 2002.

Carlotti, M.: Global-fit approach to the analysis of limb-scanning atmospheric measurements, Appl. Optics, 27, 3250-3254, 1988.

Carswell, A. I., Donovan, D. P., Bird, J. C., Duck, T. J., Pal, S. R., and Whiteway, J. A.: Measurements at the Eureka Arctic NDSC station with a Raman DIAL system, in: Advances in Atmospheric Remote Sensing with Lidar, pp. 521-524, International Committee on Laser Atmospheric Studies, 1996.

Chanin, M. L. and Hauchecorne, A.: Lidar studies of temperature and density using Rayleigh scattering, in: Handbook for MAP: Ground-Based Techniques, vol. 13, chap. 7, Scientific Commitee on Solar Terrestrial Physics, International Council of Scientific Unions, Urbana, Illinois, 1984.

Collins, R. L., Kelley, M. C., Nicolls, M. J., Ramos, C., Hou, T., Stern, T. E., Mizutani, K., and Itabe, T.: Simultaneous lidar observations of a noctilucent cloud and an internal wave in the polar mesosphere, J. Geophys. Res., 108, 8435, doi:10.1029/2002JD002427, 2003.

Croskey, C. L., Kampfer, N., Belivaqua, R. M., Hartmann, G. K., Kunzi, K. F., Schwartz, P. R., Olivero, J. J., Puliafito, S. E., Aellig, C., Umlauft, G., Waltman, W. B., and Degenhardt, W.: The Millimeter-Wave Atmospheric Sounder (MAS) - a Shuttle-based remote-sensing experiment, IEEE Microwave Theory Tech., 40, 1090-1100, 1992.

Cutler, L. J., Collins, R. L., Mizutani, K., and Itabe, T.: Rayleigh lidar observations of mesospheric inversion layers at poker flat, Alaska $\left(65^{\circ} \mathrm{N}, 147^{\circ} \mathrm{W}\right)$, Geophys. Res. Lett., 28, 1467-1470, 2001.

da Silveira, R. B., Fisch, G., Machado, L., Dall'Antonia, A., Ferando Sapucci, L., Fernandes, D., Marques, R., and Nash, J.: Executive Summary of the WMO Intercomparison of GPS Radiosondes (Brazil, 20 May to 10 June 2001), Instrument and Observing Methods Report No. 76 TD No. 1153, World Meteorological Organization, 2003.

Drummond, J. R., Houghton, J. T., Peskett, G. D., Rodgers, C. D., Wale, M. J., Whitney, J., and Williamson, E. J.: The stratospheric and mesospheric sounder on NIMBUS-7, Philos. Trans. Roy. Soc. London, 296, 219-241, 1980.

Dudhia, A. and Livesey, N.: Validation of temperature measurements from the improved stratospheric and mesospheric sounder, J. Geophys. Res., 101, 9795-9809, 1996.

Dudhia, A., Jay, V. L., and Rodgers, C. D.: Microwindow selection for high-spectral-resolution sounders, Appl. Optics, 41, 36653673, 2002.

Fischer, H., Birk, M., Blom, C., Carli, B., Carlotti, M., von Clarmann, T., Delbouille, L., Dudhia, A., Ehhalt, D., Endemann, M., Flaud, J. M., Gessner, R., Kleinert, A., Koopmann, R., Langen, J., López-Puertas, M., Mosner, P., Nett, H., Oelhaf, H., Perron, G., Remedios, J., Ridolfi, M., Stiller, G., and Zander, R.: MIPAS: an instrument for atmospheric and climate research, Atmos. Chem. Phys. Discuss., 7, 8795-8893, 2007, http://www.atmos-chem-phys-discuss.net/7/8795/2007/.

Francis, G. L., Edwards, D. P., Lambert, A., Halvorson, C. M., Lee-Taylor, J. M., and Gille, J. C.: Forward modeling and radiative transfer for the NASA EOS-Aura High Resolution Dynamics Limb Sounder (HIRDLS) instrument, J. Geophys. Res., 111, D13301, doi:10.1029/2005JD006270, 2006.

French, W. J. R., Burns, G. B., Finlayson, K., Greet, P. A., Lowe, 
R. P., and Williams, P. F. B.: Hydroxyl (6-2) airglow emission intensity ratios for rotational temperature determination, Ann. Geophys., 18, 1293-1303, 2000, http://www.ann-geophys.net/18/1293/2000/.

Froidevaux, L., Livesey, N. J., Read, W. G., , Jiang, Y. B. B., Jimenez, C., Filipiak, M. J., Schwartz, M. J., Santee, M. L., Pumphrey, H. C., Jiang, J. H., Wu, D. L., Manney, G. L., Drouin, B. J., Waters, J. W., Fetzer, E. J., Bernath, P. F., Boone, C. D., Walker, K. A., Jucks, K. W., Toon, G. C., Margitan, J. J., Sen, B., Webster, C. R., Christensen, L. E., Elkins, J. W., Atlas, E., Lueb, R. A., and Hendershot, R.: Early validation analyses of atmospheric profiles from EOS MLS on the Aura satellite, IEEE Trans. Geosci. Remote Sensing, 44, 1106-1121, 2006.

Gauthier, P. C., Charette, C., Fillion, L., Koclas, P., and Laroche, S.: Implementation of a 3D variational data assimilation system at the Canadian Meteorological Centre. Part I: The global analysis, Atmos. Ocean, 37, 103-156, 1999.

Gerding, M., Höffner, J., Rauthe, M., Singer, W., Zecha, M., and Lübken, F.-J.: Simultaneous observation of NLC, MSE and temperature at a mid-latitude station $\left(54^{\circ} \mathrm{N}\right)$, J. Geophys. Res., 112 , D12111, doi:10.1029/2006JD008135, 2007a.

Gerding, M., Höffner, J., and Rauthe, M.: Simultaneous observations of temperatures and ice-particles in the mid-latitude mesopause region, Adv. Space Res., 40, 785-793, $2007 \mathrm{~b}$.

Gettelman, A., Weinstock, E. M., Fetzer, E. J., Irion, F. W., Eldering, A., Richard, E. C., Rosenlof, K. H., Thompson, T. L., Pittman, J. V., Webster, C. R., and Herman, R. L.: Validation of Aqua satellite data in the upper troposphere and lower stratosphere with in situ aircraft instruments, Geophys. Res. Lett., 21, L22107, doi:10.1029/2004GL020730, 2004.

Gille, J. C., Bailey, P. L., Craig, R. A., House, F. B., and Anderson, G. P.: Sounding the stratosphere and mesosphere by infrared limb scanning from space, Science, 208, 397-399, 1980a.

Gille, J. C., Bailey, P. L., and Russell, J. M.: Temperature and composition measurements from the LRIR and LIMS experiments on NIMBUS-6 and NIMBUS-7, Philos. Trans. Roy. Soc. London, 296, 205-218, 1980b.

Gille, J. C., Russell, J. M., Bailey, P. L., Gordley, L. L., Remsberg, E. E., Liensch, J. H., Planet, W. G., House, F. B., Lyjak, L. V., and Beck, S. A.: Validation of temperature retrievals obtained by the Limb Infrared Monitor of the Stratosphere (LIMS) experiment on NIMBUS-7, J. Geophys. Res., 89, 5147-5160, 1984.

Gille, J. C., Bailey, P. L., Massie, S. T., Lyjak, L. V., Edwards, D. P., Roche, A. E., Kumer, J. B., Mergenthaler, J. L., Gross, M. R., Hauchecorne, A., Keckhut, P., McGee, T. J., McDermid, I. S., Miller, A. J., and Singh, U.: Accuracy and precision of cryogenic limb array etalon spectrometer (CLAES) temperature retrievals, J. Geophys. Res., 101, 9583-9601, 1996.

Greet, P. A., French, W. J. R., Burns, G. B., Williams, P. F. B., Lowe, R. P., and Finlayson, K.: $\mathrm{OH}(6-2)$ spectra and rotational temperature measurements at Davis, Antarctica, Ann. Geophys., 16, 77-89, 1998,

http://www.ann-geophys.net/16/77/1998/.

Gunson, M. R., Abbas, M. M., Abrams, M. C., Allen, M., Brown, L. R., Brown, T. L., Chang, A. Y., Goldman, A., Irion, F. W., Lowes, L. L., Mahieu, E., Manney, G. L., Michelsen, H. A., Newchurch, M. J., Rinsland, C. P., Salawitch, R. J., Stiller, G. P., Toon, G. C., Yung, Y. L., and Zander, R.: The Atmospheric Trace Molecule Spectroscopy (ATMOS) experiment: Deployment on the ATLAS Space Shuttle missions, Geophys. Res. Lett., 23, 2333-2336, 1996.

Haley, C. S. and McDade, I. C.: Procedures for recovering mesospheric and stratospheric temperatures from OSIRIS scatteredsunlight measurements, Can. J. Phys., 80, 435-442, 2002.

Hauchecorne, A. and Chanin, M.-L.: Density and temperature profiles obtained by Lidar between 35 and 70 km, J. Geophys. Res., 7, 565-568, 1980.

Hays, P. B., Abreu, V. J., Dobbs, M. E., Gell, D. A., Grassl, H. J., and Skinner, W. R.: The high-resolution Doppler imager on the Upper-Atmosphere Research Satellite, J. Geophys. Res., 98, 10713-10 723, 1993.

Hedin, A. E.: Extension of the MSIS thermosphere model into the middle and lower atmosphere, J. Geophys. Res., 96, 1159-1172, 1991.

Irion, F. W., Gunson, M. R., Toon, G. C., Chang, A. Y., Eldering, A., Mahieu, E., Manney, G. L., Michelsen, H. A., Moyer, E. J., Newchurch, M. J., Osterman, G. B., Rinsland, C. P., Salawitch, R. J., Sen, B., Yung, Y. L., and Zander, R.: Atmospheric Trace Molecule Spectroscopy (ATMOS) experiment version 3 data retrievals, Appl. Optics, 41, 6968-6979, 2002.

Ivanov, A., Kats, A., Kurnosenko, S., Nash, N., and Zaitseva, N.: International Radiosonde Intercomparison Phase III (Dzhambul, USSR 1989) final report, Tech. Rep. WMO/TD-No. 451, Instruments and Observing Methods Report 40, World Meteorological Organization, 1991.

Keckhut, P., Gelman, M. E., Wild, J. D., Tissot, F., Miller, A. J., Hauchecorne, A., Chanin, M. L., Fishbein, E. F., Gille, J., Russell, J. M., and Taylor, F. W.: Semidiurnal and diurnal temperature tides (30-55 km): Climatology and effect on UARS-LIDAR data comparisons, J. Geophys. Res., 101, 10 299-10310, 1996.

Keckhut, P., McDermid, S., Swart, D., McGee, T., GodinBeekmann, S., Adriani, A., Barnes, J., Baray, J. L., Bencherif, H., Claude, H., di Sarra, A. G., Fiocco, G., Hansen, G., Hauchecorne, A., Leblanc, T., Lee, C. H., Pal, S., Megie, G., Nakane, H., Neuber, R., Steinbrecht, W., and Thayer, J.: Review of ozone and temperature lidar validations performed within the framework of the Network for the Detection of Stratospheric Change, J. Environ. Monit., 6, 721-733, 2004.

Kerzenmacher, T. E., Walker, K. A., Strong, K., Berman, R., Bernath, P., Boone, C., Drummond, J., Fast, H., Fraser, A., MacQuarrie, K., Midwinter, C., Sung, K., McElroy, T., Mittermeier, R., Walker, J., and $\mathrm{Wu}, \mathrm{H} .:$ Measurements of $\mathrm{O}_{3}, \mathrm{NO}_{2}$ and temperature during the 2004 Canadian Arctic ACE Validation Campaign, Geophys. Res. L, 32, L16S07, doi:10.1029/ 2005GL023032, 2005.

Klekociuk, A. R., Lambert, M. M., Vincent, R. A., and Dowdy, A. J.: First year of Rayleigh lidar measurements of middle atmosphere temperatures above Davis, Antarctica, Adv. Space Res., 32, 771-776, 2003.

Kutepov, A. A., Feofilov, A. G., Marshall, B. T., Gordley, L. L., Pesnell, W. D., Goldberg, R. A., and Russell, J. M.: SABER temperature observations in the summer polar mesosphere and lower thermosphere: Importance of accounting for the $\mathrm{CO} 2$ nu(2) quanta V-V exchange, Geophys. Res. Lett., 33, L21809. doi:10.1029/2006GL026591, 2006.

Langhoff, S. R., Werner, H. J., and Rosmus, P.: Theoretical transition-probabilities for the $\mathrm{OH}$ meinel system, J. Mol. Spec., 118, 507-529, 1986. 
Laroche, S., Gauthier, P., St-James, J., and Morneau, J.: Implementation of a 3D variational data assimilation system at the Canadian Meteorological Centre. Part II: The regional analysis, Atmos. Ocean, 37, 281-307, 1999.

Leblanc, T., McDermid, I. S., Hauchecorne, A., and Keckhut, P.: Evaluation of optimization of lidar temperature analysis algorithms using simulated data, J. Geophys. Res., 103, 6177-6187, 1998.

Livesey, N. J., Read, W. G., Froidevaux, L., Waters, J. W., Santee, M. L., Pumphrey, H. C., Wu, D. L., Shippony, Z., and Jarnot, R. F.: The UARS Microwave Limb Sounder version 5 data set: Theory, characterization, and validation, J. Geophys. Res., 108, 4378, doi:10.1029/2002JD002273, 2003.

Lübken, F.-J.: Thermal structure of the Arctic summer mesosphere, J. Geophys. Res., 104, 9135-9149, 1999.

Manney, G., Daffer, W., Zawodny, J., Bernath, P., Hoppel, K., Walker, K., Knosp, B., Boone, C., Remsberg, E., Santee, M., Harvey, V. L., Pawson, S., Jackson, D., Deaver, L., Pumphrey, H., Lambert, A., Schwartz, M., Froidevaux, L., McLeod, S., Takacs, L., Suarez, M., Trepte, C., Livesey, N., Harwood, R., and Waters, J.: Solar Occultation Satellite Data and Derived Meteorological Products: Sampling Issues and Comparisons with Aura MLS, J. Geophys. Res., in press, 2007.

Manney, G. L., Daffer, W. H., Strawbridge, K. B., Walker, K. A., Boone, C. D., Bernath, P. F., Kerzenmacher, T., Schwartz, M. J., Strong, K., Sica, R. J., Kreuger, K., Pumphrey, H. C., Froidevaux, L., Lambert, A., Santee, M. L., Livesey, N. J., Remsberg, E. E., Mlynczak, M. G., and Russell, III, J. R.: The High Arctic in Extreme Winters: Vortex, Temperature, and MLS Trace Gas Evolution, Atmos. Chem. Phys. Discuss., 7, 10 235-10285, 2007.

McCormick, M. P., Hamill, P., Pepin, T. J., Chu, W. P., Swissler, T. J., and McMaster, L. R.: Satellite studies of the stratospheric aerosol, B. Am. Meteorol. Soc., 60, 1083-1046, 1979.

McElroy, C. T., Nowlan, C. R., Drummond, J. R., Bernath, P. F., Barton, D. V., Dufour, D. G., Midwinter, C., Hall, R. B., Ogyu, A., Ullberg, A., Wardle, D. I., Kar, J., Zou, J., Nichitiu, F., Boone, C. D., Walker, K. A., and Rowlands, N.: The ACEMAESTRO instrument on SCISAT: description, performance, and preliminary results, Appl. Optics, 46, 4341-4356, 2007.

McHugh, M., Magill, B., Walker, K., Boone, C., Bernath, P., and J. Russell III: Comparison of atmospheric retrievals from ACE and HALOE, Geophys. Res. Lett., 32, L15S10, doi:10.1029/2005GL022403, 2005.

Measures, R. M.: Laser remote sensing : fundamentals and applications, Wiley-Interscience, 1984.

Mertens, C. J., Mlynczak, M. G., Lopez-Puertas, M., Wintersteiner, P. P., Picard, R. H., Winick, J. R., Gordley, L. L., and Russell, J. M.: Retrieval of mesospheric and lower thermospheric kinetic temperature from measurements of $\mathrm{CO}_{2} 15 \mu \mathrm{m}$ Earth limb emission under non-LTE conditions, Geophys. Res. Lett., 28, 13911394, 2001.

Mertens, C. J., Schmidlin, F. J., Goldberg, R. A., Remsberg, E. E., Pesnell, W. D., Russell, J. M., Mlynczak, M. G., Lopez-Puertas, M., Wintersteiner, P. P., Picard, R. H., Winick, J. R., and Gordley, L. L.: SABER observations of mesospheric temperatures and comparisons with falling sphere measurements taken during the 2002 summer MaCWAVE campaign, Geophys. Res. Lett., 31, L03105, doi:10.1029/2003GL018605, 2004.
Mizutani, K., Itabe, T., Yasui, M., Aoki, T., Murayama, Y., and Collins, R. L.: Rayleigh and Rayleigh Doppler lidars for the observations of the Arctic middle atmosphere, IEICE Trans. Communications, E83B, 2004-2009, 2000.

Moreau, G., Robert, C., Catoire, V., Chartier, M., Camy-Peyret, C., Huret, N., Pirre, M., Pomathiod, L., and Chalumeau, G.: SPIRALE: a multispecies in situ balloonborne instrument with six tunable diode laser spectrometers, Appl. Optics, 44, 5972-5989, 2005.

Murtagh, D., Frisk, U., Merino, F., Ridal, M., Jonsson, A., Stegman, J., Witt, G., Eriksson, P., Jimenez, C., Megie, G., de la Noe, J., Ricaud, P., Baron, P., Pardo, J. R., Hauchcorne, A., Llewellyn, E. J., Degenstein, D. A., Gattinger, R. L., Lloyd, N. D., Evans, W. F. J., McDade, I. C., Haley, C. S., Sioris, C., von Savigny, C., Solheim, B. H., McConnell, J. C., Strong, K., Richardson, E. H., Leppelmeier, G. W., Kyrola, E., Auvinen, H., and Oikarinen, L.: An overview of the Odin atmospheric mission, Can. J. Phys., 80, 309-319, 2002.

Nadakuditi, S.: Spectral estimation of wave-driven fluctuations in Rayleigh lidar temperature measurements, Master's thesis, University of Alaska, Fairbanks, 2005.

Nakajima, H., Sugita, T., Yokota, T., Ishigaki, T., Mogi, Y., Araki, N., Waragai, K., Kimura, N., Iwazawa, T., Kuze, A., Tanii, J., Kawasaki, H., Horikawa, M., Togami, T., Uemura, N., Kobayashi, H., and Sasano, Y.: Characteristics and performance of the Improved Limb Atmospheric Spectrometer-II (ILAS-II) on board the ADEOS-II satellite, J. Geophys. Res., 111, D11S01, doi:10.1029/2005JD006334, 2006.

Nash, J. and Schmidlin, F. J.: International Radiosonde Intercomparison (U.K., 1984, USA, 1985) final report, Tech. Rep. WMO/TD-No. 195, Instruments and Observing Methods Report 30, World Meteorological Organization, 1987.

Nash, J., Smout, R., Oakley, T., and Pathack, B.: WMO intercomparison of radiosonde systems (Vacoas, Mauritius, 2-25 February 2005), Instrument and Observing Methods Report No. 83 TD No. 1303, World Meteorological Organization, 2006.

Nowlan, C. R., McElroy, C. T., and Drummond, J. R.: Measurements of the $\mathrm{O}_{2} A$ - and $B$-bands for determining temperature and pressure profiles from ACE-MAESTRO: Forward model and retrieval algorithm, J. Quan. Spec. \& Rad. Trans., 108, 371-388, 2007.

Offermann, D., Grossmann, K. U., Barthol, P., Knieling, P., Riese, M., and Trant, R.: Cryogenic Infrared Spectrometers and Telescopes for the Atmosphere (CRISTA) experiment and middle atmosphere variability, J. Geophys. Res., 104, 15 311-16325, 1999.

Ortland, D. A., Hays, P. B., Skinner, W. R., and Yee, J. H.: Remote sensing of mesospheric temperature and $\mathrm{O}_{2}\left({ }^{1} \Sigma\right)$ band volume emission rates with the high-resolution Doppler imager, J. Geophys. Res., 103, 1821-1835, 1998.

Petelina, S. V., Degenstein, D. A., Llewellyn, E. J., Lloyd, N. D., Mertens, C. J., Mlynczak, M. G., and Russell, J. M.: Thermal conditions for PMC existence derived from Odin/OSIRIS and TIMED/SABER data, Geophys. Res. Lett., 32, L17813, doi:10.1029/2005GL023099, 2005.

Raspollini, P., Belotti, C., Burgess, A., Carli, B., Carlotti, M., Ceccherini, S., Dinelli, B. M., Dudhia, A., Flaud, J. M., Funke, B., Hopfner, M., Lopez-Puertas, M., Payne, V., Piccolo, C., Remedios, J. J., Ridolfi, M., and Spang, R.: MIPAS level 2 operational 
analysis, Atmos. Chem. Phys., 6, 5605-5630, 2006, http://www.atmos-chem-phys.net/6/5605/2006/.

Rauthe, M., Gerding, M., Höffner, J., and Lübken, F. J.: Lidar temperature measurements of gravity waves over Kühlungsborn $\left(54^{\circ} \mathrm{N}\right)$ from 1 to $105 \mathrm{~km}$ : A winter-summer comparison, J. Geophys. Res., 111, D24108, doi:10.1029/2006JD007354, 2006.

Remsberg, E., Lingenfelser, G., Harvey, V. L., Grose, W., Russell, J., Mlynczak, M., Gordley, L., and Marshall, B. T.: On the verification of the quality of SABER temperature, geopotential height, and wind fields by comparison with Met Office assimilated analyses, J. Geophys. Res., 108, 4628, doi:10.1029/2003JD003720, 2003.

Ridal, M., Murtagh, D. P., Merino, F., Pardo, J. R., and Pagani, L.: Microwave temperature and pressure measurements with the Odin satellite: II. Retrieval method, Can. J. Phys., 80, 455-467, 2002.

Ridolfi, M., Carli, B., Carlotti, M., von Clarmann, T., Dinelli, B. M., Dudhia, A., Flaud, J. M., Hopfner, M., Morris, P. E., Raspollini, P., Stiller, G., and Wells, R. J.: Optimized forward model and retrieval scheme for MIPAS near-real-time data processing, Appl. Optics, 39, 1323-1340, 2000.

Ridolfi, M., Blum, U., Carli, B., Catoire, V., Ceccherini, S., Claude, H., Clercq, C. D., Fricke, K. H., Friedl-Vallon, F., Iarlori, M., Keckhut, P., Kerridge, B., Lambert, J.-C., Meijer, Y. J., Mona, L., Oelhaf, H., Pappalardo, G., Pirre, M., Rizi, V., Robert, C., Swart, D., von Clarmann, T., Waterfall, A., and Wetzel, G.: Geophysical validation of temperature retrieved by the ESA processor from MIPAS/ENVISAT atmospheric limb-emission measurements, Atmos. Chem. Phys., 7, 4459-4487, 2007, http://www.atmos-chem-phys.net/7/4459/2007/.

Riese, M., Spang, R., Preusse, P., Ern, M., Jarisch, M., Offermann, D., and Grossmann, K. U.: Cryogenic Infrared Spectrometers and Telescopes for the Atmosphere (CRISTA) data processing and atmospheric temperature and trace gas retrieval, J. Geophys. Res., 104, 16349-16367, 1999.

Rodgers, C. D., Jones, R. L., and Barnett, J. J.: Retrieval of temperature and composition from NIMBUS-7 SAMS measurements, J. Geophys. Res., 89, 5280-5286, 1984.

Rothman, L. S., Jacquemart, D., Barbe, A., Benner, D. C., Birk, M., Brown, L. R., Carleer, M. R., Chackerian, C., Chance, K., Coudert, L. H., Dana, V., Devi, V. M., Flaud, J. M., Gamache, R. R., Goldman, A., Hartmann, J. M., Jucks, K. W., Maki, A. G., Mandin, J. Y., Massie, S. T., Orphal, J., Perrin, A., Rinsland, C. P., Smith, M. A. H., Tennyson, J., Tolchenov, R. N., Toth, R. A., Auwera, J. V., Varanasi, P., and Wagner, G.: The HITRAN 2004 molecular spectroscopic database, J. Quan. Spec. Rad. Trans., 96, 139-204, 2005.

Russell, J. M., Gordley, L. L., Parks, J. H., Drayson, S. R., Hesketh, W. D., Cicerone, R. J., Tuck, A. F., Frederick, J. E., Harries, J. E., and Crutzen, P. J.: The halogen occultation experiment, J. Geophys. Res., 98, 10777-10797, 1993.

Russell, J. M., Mlynczak, M. G., Gordley, L. L., Tansock, J. J., and Esplin, R. W.: An overview of the SABER experiment and preliminary calibration resuts, Proceedings of SPIE, 44th Annual Meeting, 3756, 277-288, 1999.

Salby, M.: Fundamentals of Atmospheric Physics, Academic Press, New York, 1996.

Schwartz, M. J., Lambert, A., Manney, G. L., Read, W. G., Livesey, N. J., Froidevaux, L., Ao, C. O., Bernath, P. F., Boone, C. D.,
Cofield, R. E., Daffer, W. H., Drouin, B. J., Fetzer, E. J., Fuller, R. A., Jarnot, R. F., Jiang, J. H., Jiang, Y. B., Knosp, B. W., Krüger, K., Li, J.-L. F., Mlynczak, M. G., Pawson, S., Russell III, J. M., Santee, M. L., Snyder, W. V., Stek, P. C., Thurstans, R. P., Tompkins, A. M., Wagner, P. A., Walker, K. A., Waters, J. W., and Wu, D. L.: Validation of the Aura Microwave Limb Sounder Temperature and Geopotential Height Measurements, J. Geophys. Res., accepted, 2007.

Sica, R. J., Sargoytchev, S., Argall, P. S., Borra, E. F., Girard, L., Sparrow, C. T., and Flatt, S.: Lidar measurements taken with a large-aperture liquid mirror. 1. Rayleigh-scatter system, Appl. Optics, 34, 6925-6936, 1995.

Sica, R. J., Zylawy, Z. A., and Argall, P. S.: Ozone corrections for Rayleigh-scatter temperature determinations in the middle atmosphere, J. Atmos. Ocean. Technol., 18, 1223-1228, 2001.

Sica, R. J., Thayaparan, T., Argall, P. S., Russell, A. T., and Hocking, W. K.: Modulation of upper mesospheric temperature inversions due to tidal-gravity wave interactions, J. Geophys. Res., 64, 915-922, 2002.

Stiller, G. P., Gunson, M. R., Lowes, L. L., Abrams, M. C., Raper, O. F., Farmer, C. B., Zander, R., and Rinsland, C. P.: Stratospheric and mesospheric pressure-temperature profiles from rotational analysis of $\mathrm{CO}_{2}$ lines in atmospheric trace molecule spectroscopy ATLAS-1 infrared solar occultation spectra, J. Geophys. Res., 100, 3107-3117, 1995.

Sugita, T., Yokota, T., Nakajima, H., Kobayashi, H., Saitoh, N., Kawasaki, H., Usami, M., Saeki, H., Horikawa, M., and Sasano, Y.: A comparative study of stratospheric temperatures between ILAS-II and other data, Proceedings of SPIE, Passive Optical Remote Sensing of the Atmosphere and Clouds IV, 5652, 279289, 2004.

Taylor, F. W., Rodgers, C. D., Whitney, J. G., Werrett, S. T., Barnett, J. J., Peskett, G. D., Venters, P., Ballard, J., Palmer, C. W. P., Knight, R. J., Morris, P., Nightingale, T., and Dudhia, A.: Remote-sensing of atmospheric structure and composition by pressure modulator radiometry from space - the ISAMS experiment on UARS, J. Geophys. Res., 98, 10 799-10 814, 1993.

von Clarmann, T.: Validation of remotely sensed profiles of atmospheric state variables: strategies and terminology, Atmos. Chem. Phys., 6, 4311-4320, 2006,

http://www.atmos-chem-phys.net/6/4311/2006/.

von Engeln, A., Langen, J., Wehr, T., Buhler, S., and Kunzi, K.: Retrieval of upper stratospheric and mesospheric temperature profiles from Millimeter-Wave Atmospheric Sounder data, J. Geophys. Res., 103, 31 735-31 748, 1998.

von Zahn, U. and Höffner, J.: Mesopause temperature profiling by potassium lidar, Geophys. Res. Lett., 23, 141-144, 1996.

Wang, W.: Spectral estimation of signal and noise power in Rayleigh lidar measurements of the middle atmosphere, Master's thesis, University of Alaska, 2003.

Waters, J. W., Froidevaux, L., Harwood, R. S., Jarnot, R. F., Pickett, H. M., Read, W. G., Siegel, P. H., Cofield, R. E., Filipiak, M. J., Flower, D. A., Holden, J. R., Lau, G. K., Livesey, N. J., Manney, G. L., Pumphrey, H. C., Santee, M. L., Wu, D. L., Cuddy, D. T., Lay, R. R., Loo, M. S., Perun, V. S., Schwartz, M. J., Stek, P. C., Thurstans, R. P., Boyles, M. A., Chandra, K. M., Chavez, M. C., Chen, G. S., Chudasama, B. V., Dodge, R., Fuller, R. A., Girard, M. A., Jiang, J. H., Jiang, Y. B., Knosp, B. W., LaBelle, R. C., Lam, J. C., Lee, K. A., Miller, D., Oswald, J. E., Patel, 
N. C., Pukala, D. M., Quintero, O., Scaff, D. M., Snyder, W. V., Tope, M. C., Wagner, P. A., and Walch, M. J.: The Earth Observing System Microwave Limb Sounder (EOS MLS) on the Aura satellite, IEEE Trans. Geosci. Remote Sensing, 44, 1075-1092, 2006.
Yamamori, M., Kagawa, A., Kasai, Y., Mizutani, K., Murayama, Y., Sugita, T., Irie, H., and Nakajima, H.: Validation of ILAS-II version $1.4 \mathrm{O}-3, \mathrm{HNO} 3$, and temperature data through comparison with ozonesonde, ground-based FTS, and lidar measurements in Alaska, J. Geophys. Res., 111, D11S08, doi:10.1029/2005JD006438, 2006. 